\title{
ANTIVIRALS AND ANTIVIRAL STRATEGIES
}

Erik De Clercq

Abstract | In recent years, the demand for new antiviral strategies has increased markedly. There are many contributing factors to this increased demand, including the ever-increasing prevalence of chronic viral infections such as HIV and hepatitis $B$ and $C$, and the emergence of new viruses such as the SARS coronavirus. The potential danger of haemorrhagic fever viruses and eradicated viruses such as variola virus being used as bioterrorist weapons has also increased the profile of antiviral drug discovery. Here, the virus infections for which antiviral therapy is needed and the compounds that are available, or are being developed, for the treatment of these infections are described.

Interest in the development of new antiviral compounds is mainly fuelled by two considerations: what is the requirement for a specific antiviral drug against the virus infection concerned (and, linked to this, could it reasonably be expected that the virus infection would be controlled by using the antiviral drug); and which antiviral drugs are available to treat or prevent the virus infection concerned (or which antiviral strategies could be pursued to meet the demand). The purpose of this article is to examine how different virus infections should be approached from a therapeutic viewpoint not only those virus infections that we are familiar with, but also new or old virus infections that could emerge or re-emerge, respectively. The basic strategies that are used to design antiviral drugs have been described previously ${ }^{1}$. Here, I will evaluate their usefulness, or potential usefulness, in the control of virus infections. The antiviral drugs that have been formally licensed for medical use are listed in BOX 1 . The chemical structures of some of the compounds discussed in this article are shown in FIG. 1; the remaining compounds that are discussed are shown in online supplementary information S1 (figure). The viral and/or cellular targets for antiviral agents and potential antiviral agents are presented in TABLE 1 .

\section{Parvovirus infections}

The only parvovirus that is pathogenic for humans is $\mathrm{B} 19$, which is responsible for so-called fifth disease, or erythema infectiosum, in children. Although complications such as arthritis, aplastic crisis (reticulocytopoenia), myocarditis and hydrops fetalis (during pregnancy) can occur after infection with B19 virus, no serious attempts have been made to develop either preventative or therapeutic measures for B19-virusassociated disease and the question of whether any efforts should be made to develop a vaccine or cure for this disease remains open to debate.

\section{Polyomavirus infections}

The polyomaviruses JC and BK viruses have been associated with, and are thought to be responsible for, progressive multifocal leukoencephalopathy (PML) and haemorrhagic cystitis, respectively, in patients with AIDS. Several anecdotal case reports have indicated that cidofovir [(S)-1-(3-hydroxy-2phosphonylmethoxypropyl)cytosine (HPMPC)] is effective in the treatment of PML in AIDS patients ${ }^{2}$ if it is given at the dosage recommended for the treatment of human cytomegalovirus (HCMV) retinitis in AIDS patients - intravenously, $5 \mathrm{mg} \mathrm{kg}^{-1}$ week $^{-1}$ for 2 weeks then $5 \mathrm{mg} \mathrm{kg}^{-1}$ every 2 weeks, with concomitant probenecid administration. The activity of cidofovir against both primate and murine polyomaviruses has been demonstrated in cell culture in vitro ${ }^{3}$. So far, no other antiviral drugs have been proven to be effective against polyomavirus infections. 


\section{Box 1 | Approved antiviral drugs}

\section{HIV infections}

Nucleoside reverse transcriptase inhibitors (NRTIs):

Zidovudine: $3^{\prime}$-azido-2', $3^{\prime}$-dideoxythymidine (AZT) I Didanosine: $2^{\prime}, 3^{\prime}$-dideoxyinosine (ddI) I Zalcitabine: 2', 3'-

dideoxycytidine (ddC) I Stavudine: $2^{\prime}, 3^{\prime}$-dideoxy-2', $3^{\prime}$-didehydrothymidine (d4T) I Lamivudine: (-)- $\beta$ - - - $3^{\prime}$-thia- $2^{\prime}, 3^{\prime}$ dideoxycytidine (3TC) I Abacavir (ABC): 2-amino-6-cyclopropylaminopurin-9-yl-2-cyclopentene I Emtricitabine:

(-)- $\beta$-L-3'-thia-2', $3^{\prime}$-dideoxy-5-fluorocytidine ((-)-FTC)

Nucleotide reverse transcriptase inhibitors (NtRTIs):

Tenofovir disoproxil: bis(isopropoxycarbonyloxymethyl)ester of ( $R$ )-9-(2-phosphonylmethoxypropyl)adenine

Non-nucleoside reverse transcriptase inhibitors (NNRTIs):

Nevirapine I Delavirdine I Efavirenz

Protease inhibitors (PIs):

Saquinavir | Ritonavir | Indinavir | Nelfinavir | Amprenavir | Lopinavir | Atazanavir

Fusion inhibitors (FIs):

Enfuvirtide : Pentafuside (T-20)

HBV infections

Lamivudine I Adefovir dipivoxil: bis(pivaloyloxymethyl)ester of 9-(2-phosphonylmethoxyethyl)adenine

HSV and VZV infections

Acyclovir and its oral prodrug valaciclovir I Penciclovir and its oral prodrug famciclovir | Idoxuridine: 5-iodo-2'deoxyuridine (IDU) I Trifluridine: 5-trifluoro-2'-deoxythymidine (TFT) I Brivudin: (E)-5-(2-bromovinyl)-2'deoxyuridine (BVDU)

\section{CMV infections}

Ganciclovir and its oral prodrug valganciclovir I Foscarnet: phosphonoformic acid (PFA) trisodium salt I Cidofovir: (S)-1-(3-hydroxy-2-phosphonylmethoxypropyl)cytosine (HPMPC) I Fomivirsen: antisense (phosphorothioate) oligonucleotide

Influenza virus infections

Amantadine | Rimantadine | Zanamivir | Oseltamivir

HCV infections

(Pegylated) IFN- $\alpha$ | Ribavirin

\section{Papillomavirus infections}

There are several clinical manifestations of human papillomavirus (HPV) infection, which include verruca vulgaris, plantar warts, hypopharyngeal, oesophageal, laryngeal and respiratory papillomatosis, genital warts (condylomata acuminata), cervical intraepithelial neoplasia (CIN) (which can develop into cervical carcinoma), vulvar intraepithelial neoplasia (VIN), penile intraepithelial neoplasia (PIN) and perianal intraepithelial neoplasia (PAIN). When injected intralesionally or applied topically as a $1 \%$ gel or cream, cidofovir has proved highly efficacious in causing regression of many HPV-associated lesions (including laryngeal papillomas and anogenital warts) with no or few recurrences. Any recurrences have responded promptly to another course of cidofovir therapy ${ }^{2}$. The inhibitory effect of cidofovir on the proliferation of HPV-infected cells could be attributed to the induction of apoptosis in these cells ${ }^{4}$ and there is evidence that cidofovir restores p53 function in HPV-associated cancers ${ }^{5}$.

Two other antiviral agents have specificity for HPV infections - the acyclic nucleoside phosphonate analogues PMEG [9-(2-phosphonylmethoxyethyl)guanine] and cPr-PMEDAP [9-(2-phosphonylmethoxyethyl)- $N^{5}$ cyclopropyl-2,6-diaminopurine], which selectively inhibit HPV-16-positive cells in organotypic co-cultures of primary normal human keratinocytes with cervical carcinoma cells ${ }^{6}$.

\section{Adenovirus infections}

Adenovirus infections in immunocompetent individuals are generally self-limiting, and neither preventative nor therapeutic measures (vaccination or antiviral therapy) are used. However, in allogeneic haematopoietic stem-cell transplant (HSCT) recipients, adenovirus infections can be severe. In these patients, according to anecdotal reports, cidofovir has been shown to be to be effective in suppressing adenovirus infection, whereas ribavirin and vidarabine have not ${ }^{7}$. At present, cidofovir seems to be the only antiviral drug that could be successfully used to treat adenovirus infections, particularly in HSCT recipients².

\section{$\alpha$-herpesvirus infections}

The $\alpha$-herpesviruses include herpes simplex virus types 1 and 2 (HSV-1 and HSV-2) and varicella-zoster virus (VZV). They can cause both primary infections (for example, HSV-1 causes gingivostomatitis, encephalitis and eczema herpeticum, HSV-2 causes genital and neonatal herpes, and VZV causes varicella (chicken-pox)) and recurrent infections (for example, HSV-1 causes herpes labialis and herpetic keratitis, HSV-2 causes genital herpes and VZV causes herpes zoster). These viruses can also cause severe, disseminated or progressive mucocutaneous infections in immunosuppressed patients.

Adequate treatments that are available for $\alpha$-herpesvirus infections ${ }^{8}$ include: acyclovir and its oral prodrug 
<smiles>Nc1ccn(C2COCO2)c(=O)n1</smiles>

\section{Lamivudine}

Anti-HIV nucleoside

reverse transcriptase (RT) inhibitor (NRTI)

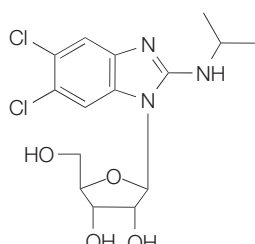

Maribavir

Anti-CMV nuclear egress inhibitor

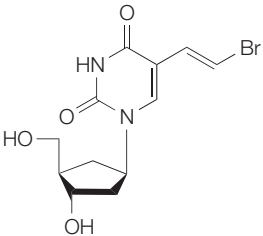

Brivudin

Anti-VZV DNA

polymerase inhibitor<smiles></smiles>

Valaciclovir

Anti-HSV DNA

polymerase inhibitor<smiles>CC(C)C(N)C(=O)OCC(CO)OCn1cnc2c(=O)[nH]c(N)nc21</smiles>

Valganciclovir Anti-CMV DNA polymerase inhibitor<smiles>Nc1ccn(C[C@H](CO)OCP(=O)(O)O)c(=O)n1</smiles>

Cidofovir

Broad-spectrum anti-DNA virus

DNA polymerase inhibitor

$\mathrm{OH}$

Entecavir

Anti-HBV DNA polymerase inhibitor

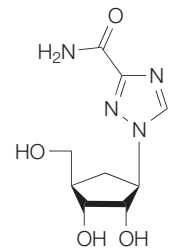

Ribavirin

Anti-HCV IMP

dehydrogenase inhibitor<smiles>CCOC(=O)C1=CC(OC(CC)CC)[C@H](NC(C)=O)C(NC(=N)N)C1</smiles>

Oseltamivir

Anti-influenza virus neuraminidase inhibitor

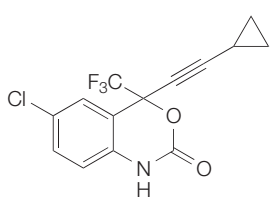

Efavirenz

Anti-HIV non-nucleoside RT inhibitor (NNRTI)<smiles>CC(C)OC(=O)OCOP(=O)(CO[C@H](C)Cn1cnc2c(N)ncnc21)OCOC(=O)OC(C)C</smiles>

Tenofovir disoproxil fumarate Anti-HIV nucleotide RT inhibitor (NtRTI)

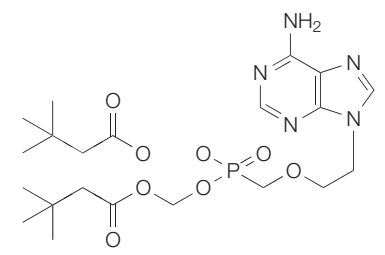

Adefovir dipivoxil Anti-HBV NtRTI

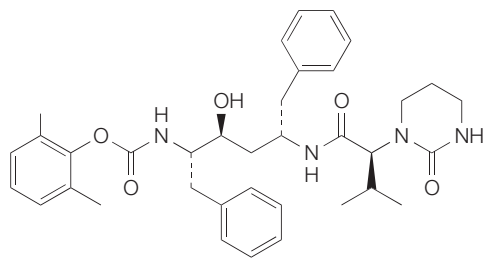

Lopinavir

Anti-HIV protease inhibitor (PI)

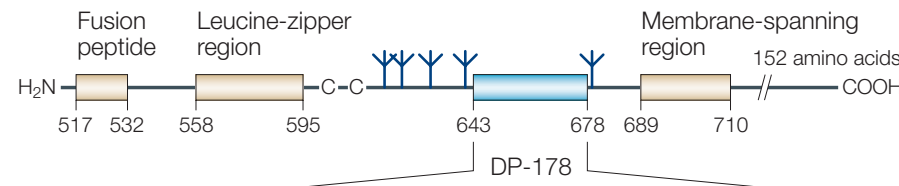

YTSLIHSLIEESQNQQEKNEQELLELDKWASLWNWE

\section{Enfuvirtide}

Anti-HIV fusion inhibitor (FI)<smiles>Cc1cc(CCCOc2c(C)cc(-c3noc(C(F)(F)F)n3)cc2C)on1</smiles>

S-1360

Anti-HIV integrase inhibitor
Pleconaril

Anti-picornavirus capsid binder<smiles></smiles>

$\mathrm{H}_{3} \mathrm{C}-\mathrm{O}$

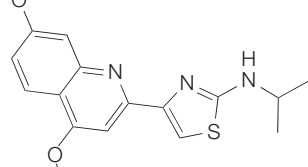

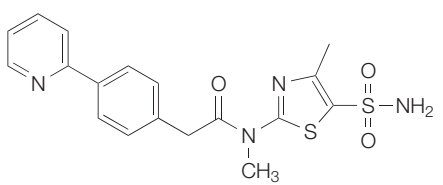

BAY 57-1293

Anti-HSV helicase-primase inhibitor<smiles>Cc1cc(C#N)cc(C)c1Oc1nc(Nc2ccc(C#N)cc2)nc(N)c1Br</smiles>

Etravirine Anti-HIV NNRTI

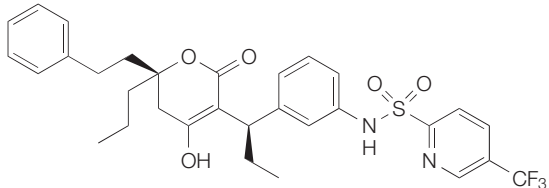

Tipranavir

Anti-HIV non-peptidomimetic PI

Figure 1 | Structures of selected licensed antiviral drugs and compounds still in clinical or preclinical development. For further detail, see REF. 8. For structures of the other compounds discussed in this article, see online supplementary information S1 (figure). 


\begin{tabular}{|c|c|c|c|}
\hline Virus & Viral target & Cellular target & Comments \\
\hline Parvovirus & DNA polymerase & - & Remains to be explored \\
\hline Polyomavirus & DNA polymerase & - & Remains to be explored \\
\hline Papillomavirus & DNA polymerase, E6, E7 & - & Remains to be explored \\
\hline Adenovirus & DNA polymerase & Cell-associated factors & Remains to be explored \\
\hline $\begin{array}{l}\alpha \text {-herpesvirus } \\
(\mathrm{HSV}-1, \mathrm{HSV}-2, \mathrm{VZV})\end{array}$ & $\begin{array}{l}\text { Thymidine kinase } \\
\text { DNA polymerase } \\
\text { Helicase-primase }\end{array}$ & - & $\begin{array}{l}\text { Target for activation } \\
\text { Target for inhibition } \\
\text { Target for inhibition }\end{array}$ \\
\hline $\begin{array}{l}\beta \text {-herpesvirus } \\
(\mathrm{HCMV}, \mathrm{HHV}-6, \mathrm{HHV}-7)\end{array}$ & $\begin{array}{l}\text { Protein kinase } \\
\text { DNA polymerase } \\
\text { Terminase }\end{array}$ & - & $\begin{array}{l}\text { Target for activation } \\
\text { Target for inhibition } \\
\text { Target for inhibition }\end{array}$ \\
\hline$\gamma$-herpesvirus (EBV, HHV-8) & DNA polymerase & - & Target for inhibition \\
\hline $\begin{array}{l}\text { Poxvirus (for example, variola and } \\
\text { vaccinia viruses) }\end{array}$ & DNA and RNA polymerases & Several ${ }^{*}$ & Remains to be explored \\
\hline Hepadnavirus (HBV) & $\begin{array}{l}\text { DNA polymerase } \\
\text { (Reverse transcriptase) }\end{array}$ & - & Target for inhibition \\
\hline $\begin{array}{l}\text { Picornavirus } \\
\text { (Enteroviruses and Rhinoviruses) }\end{array}$ & $\begin{array}{l}\text { Viral capsid } \\
\text { RNA polymerase }\end{array}$ & - & $\begin{array}{l}\text { Target for inhibition } \\
\text { Remains to be explored }\end{array}$ \\
\hline $\begin{array}{l}\text { Flavivirus (for example, yellow fever } \\
\text { and dengue viruses) }\end{array}$ & RNA polymerase & - & Remains to be explored \\
\hline Arenavirus (for example, Lassa) & RNA polymerase & Several* & Remains to be explored \\
\hline $\begin{array}{l}\text { Bunyavirus (for example, } \\
\text { Crimean-Congo) }\end{array}$ & RNA polymerase & Several* & Remains to be explored \\
\hline $\begin{array}{l}\text { Togavirus (for example, Western } \\
\text { Equine encephalitis virus) }\end{array}$ & RNA polymerase & Several* & Remains to be explored \\
\hline Rhabdovirus (Rabies virus) & RNA polymerase & Several $^{\star}$ & Remains to be explored \\
\hline Filovirus (for example, Ebola virus) & RNA polymerase & Several* & Remains to be explored \\
\hline Hepacivirus (HCV) & $\begin{array}{l}\text { RNA polymerase, } \\
\text { RNA helicase, } \\
\text { Viral protease }\end{array}$ & - & Being investigated \\
\hline Orthomyxovirus (Influenza) & $\begin{array}{l}\text { Matrix (M2) protein } \\
\text { Neuraminidase }\end{array}$ & - & $\begin{array}{l}\text { Target for inhibition } \\
\text { Target for inhibition }\end{array}$ \\
\hline Paramyxovirus (RSV) & Fusion polypeptide & Several* & Being explored \\
\hline Coronavirus (SARS-CoV) & Several ${ }^{\ddagger}$ & - & Being explored \\
\hline Reovirus (Rotavirus) & - & Several* & Remains to be explored \\
\hline Retrovirus (HIV) & Several\$॥ & Several" & $\begin{array}{l}\text { Established or being } \\
\text { explored }\end{array}$ \\
\hline
\end{tabular}

*Inosine 5'-monophosphate (IMP) dehydrogenase, S-adenosylhomocysteine (SAH) hydrolase, oritidine 5'-phosphate (OMP) decarboxylase and cytosine 5'-triphosphate (CTP) synthetase. ₹Spike (S) protein, RNA polymerase (replicase), RNA helicase and viral protease. \$Fusion polypeptide (viral glycoprotein gp41), reverse transcriptase and viral protease. IViral glycoprotein gp120, integrase and transcription transactivator (TAT). "Integration- and transcription-associated factors.

valaciclovir; penciclovir and its oral prodrug famciclovir; and brivudin (BVDU). BVDU has now been licensed in several European countries for the treatment of herpes zoster. Acyclovir and penciclovir are acyclic nucleoside analogues; in addition, some carbocyclic guanosine analogues (such as A-5021 and cyclohexenylguanine) and methylenecyclopropane analogues of nucleosides (such as synguanol), have been accredited with potent activity against HSV-1, HSV-2 and VZV ${ }^{9}$. Some of the methylenecyclopropane analogues have also proved effective against $\beta$ - and $\gamma$-herpesviruses and hepatitis $B$ virus $(\mathrm{HBV})^{10,11}$.

As acyclic nucleoside analogues require phosphorylation by the virus-encoded thymidine kinase (TK) to exert their antiviral activity (FIG. 2), they do not inhibit the TK-deficient HSV or VZV strains that can occasionally arise, particularly in immunocompromised hosts. In this situation, infections should be treated with foscarnet, a pyrophosphate analogue, or the acyclic nucleoside phosphonate cidofovir, neither of which depend on the HSV or VZV TK for their antiviral action (FIG. 3).

Also dependent on the activity of a viral TK, but specifically the VZV-encoded TK, are the bicyclic furo(2,3-d)pyrimidine nucleoside analogues (BCNAs) Cf 1368, Cf 1369, Cf 1743 and Cf 1742 . These compounds inhibit VZV replication at subnanomolar concentrations and, even at 100,000-fold greater concentrations, are not toxic to host cells ${ }^{12,13}$. Unlike the 'classical' anti-VZV compounds, the BCNAs are selective for VZV and are therefore inactive against HSV-1 and HSV-2. The alkyl(phenyl) side chain on the furanyl ring of the BCNAs is an important determinant of the specificity of these compounds ${ }^{14}$. 


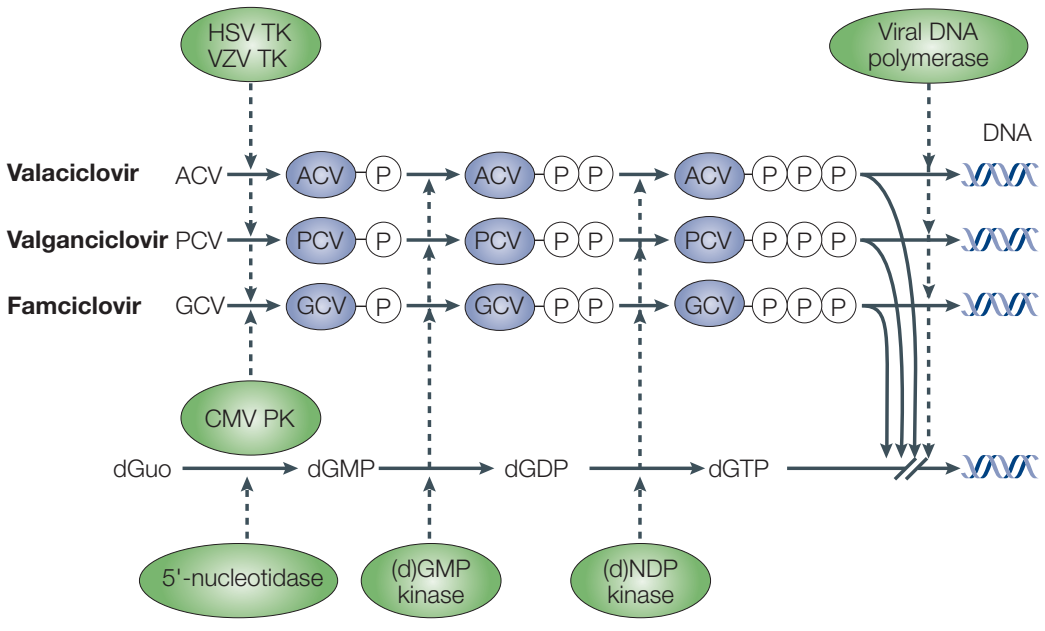

Figure 2 | The mechanism of action of acyclic nucleoside analogues. Examples of these compounds include acyclovir and its oral prodrug valaciclovir, penciclovir and its oral prodrug famciclovir, and ganciclovir and its oral prodrug valganciclovir. These acyclic nucleoside analogues require phosphorylation by the viral thymidine kinase (TK) to exert their antiviral activity for HSV and VZV (valaciclovir and famciclovir) and a protein kinase (PK; UL97) for CMV (valganciclovir).

New anti-HSV agents that target the viral helicase-primase complex ${ }^{15}$ - the thiazolylphenyl derivatives BILS 179BS and BAY 57-1293 — were recently reported to have in vivo efficacy in animal models of HSV-1 and HSV-2 infection ${ }^{16,17}$. These compounds seem to function by enhancing the affinity of the helicase-primase complex for the HSV DNA. This complex comprises three viral proteins - the HSV UL5, UL8 and UL52 gene products (FIG. 3) — which together unwind the double-stranded viral DNA and generate primers for DNA synthesis by the viral DNA polymerase. The antiviral potency of BAY $57-1293$ is reported to be superior to all compounds that are currently used to treat HSV infections ${ }^{18}$. These data validate the further pursuit of helicase-primase inhibitors for the treatment of HSV infections.

\section{$\beta$-herpesvirus infections}

Among the $\beta$-herpesviruses - HCMV, human herpesvirus type 6 (HHV-6), and human herpesvirus type 7 (HHV-7) - HCMV is associated with the primary infections CMV mononucleosis and congenital cytomegalic inclusion disease, as well as recurrent infections, such as pneumonitis, hepatitis, retinitis, encephalitis and colitis in immunocompromised hosts.

Five compounds have been licensed to treat HCMV infections - ganciclovir, its oral prodrug valganciclovir, foscarnet, cidofovir and fomivirsen. With the exception of fomivirsen, which targets HCMV immediate-early mRNA, these compounds target the viral DNA polymerase. Ganciclovir must first be phosphorylated by the HCMV-encoded protein kinase, the UL97 gene product (FIG.2), which is also the main site for mutations that engender resistance towards this compound.

The available anti-HCMV drugs have several drawbacks that limit their clinical utility. Fomivirsen must be injected intraocularly (that is, intravitreally), foscarnet must be given intravenously three times daily and cidofovir is also administered intravenously, albeit once weekly or every other week. Nephrotoxicity is the dose-limiting factor for cidofovir and foscarnet, whereas bone-marrow suppression that results in granulocytopoenia and thrombocytopoenia is the most common toxic side effect seen with ganciclovir.

Taken together, these considerations justify the search for new anti-HCMV agents that are less toxic and/or more effective. A possible lead compound is 2-chloro-3-pyridin-3-yl-5,6,7,8-tetrahydroindolizine-1carboxamide (CMV423), which was recently shown to have potent in vitro activity against a wide range of HCMV reference strains and clinical isolates, including those that had acquired resistance to ganciclovir, foscarnet or cidofovir ${ }^{19}$. CMV423 targets a step of the viral replication cycle before the DNA polymerase step and probably coincides with immediate-early antigen expression.

The 'non-nucleoside' 4-hydroxyquinoline carboxamides (PNU-181465) ${ }^{20}$ and 4-oxo-dihydroquinolines (PNU-182171 and PNU-183792)21 interact with the $\beta$-herpesvirus DNA polymerase. These compounds do not inhibit the cellular DNA polymerases ( $\alpha$ and $\delta$ ) or the mitochondrial DNA polymerase $\gamma$. HSV- 1 and HSV-2 viruses that are resistant to these compounds have been found to have a single amino acid change of valine to alanine within conserved domain III of the HSV-1 and HSV-2 DNA polymerases. This valine residue (V823 in HSV-1) is conserved in the DNA polymerases of six of the eight human herpesviruses and seems to have a crucial role in the observed antiherpesvirus effects of these compounds. The DNA polymerase in HHV-6 contains an alanine at this position and accordingly is not inhibited.

The HCMV terminase, which comprises the UL89 and UL56 gene products, is a target for chemotherapeutic intervention. Together, these gene products cleave the viral high-molecular-weight DNA concatamers into unit-length genomes and package these monomeric genomes into viral procapsids. Intervention at this stage is expected to block viral DNA cleavage and packaging, leading to an accumulation of empty procapsids and unprocessed concatameric DNA, as has been demonstrated with the (naphthylsulphonylamino)phenylpropanamide BAY 38-4766 (REF. 22). BAY 38-4766 targets a viral DNA maturation step that does not occur in uninfected eukaryotic cells, so targeting the viral terminase is an attractive strategy to combat HCMV infections. In addition to BAY 38-4766, two benzimidazole ribonucleosides - 1-( $\beta$-D-ribofuranosyl)-2-bromo-5,6-dichlorobenzimidazole (BDCRB) and 1-( $\beta$-D-ribofuranosyl)-2,5,6-dichlorobenzimidazole (TCRB) - have also been shown to inhibit cleavage and encapsidation of viral DNA, and amino acid mutations in both the UL89 and UL56 gene products have been identified in resistant strains of $\mathrm{HCMV}^{23}$.

Maribavir (or 1263W94) is another benzimidazole ribonucleoside, in which, in addition to a switch from a $\mathrm{D}$ to $\mathrm{L}$ configuration, the halogen at position 2 of the benzimidazole is replaced by an isopropylamine, and this compound also has prominent anti-HCMV activity. In 
a<smiles>Nc1ccn(CC(CO)OCc2ccccc2)c(=O)n1</smiles><smiles>C1CCC1</smiles>
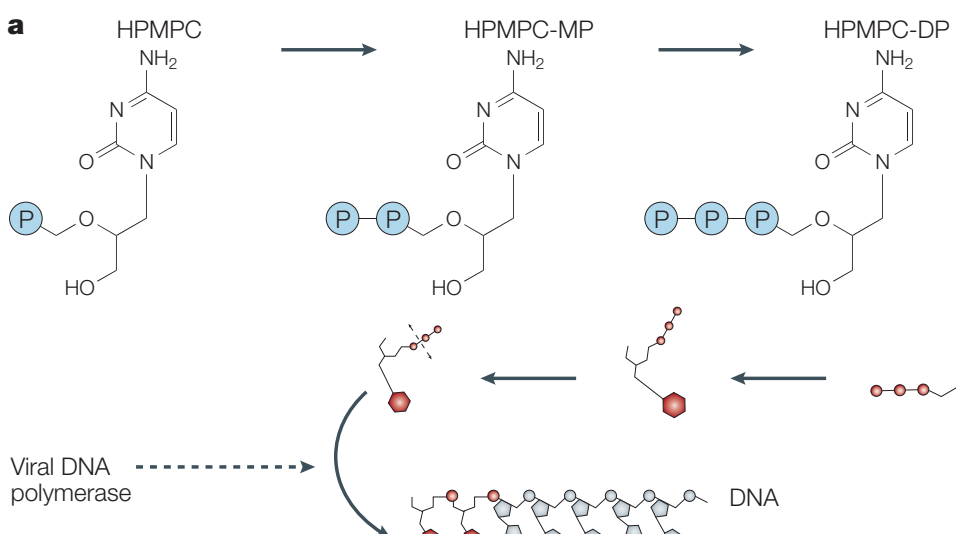

a a o ba a

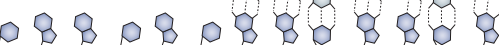

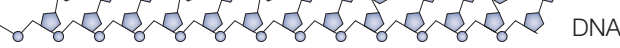

b

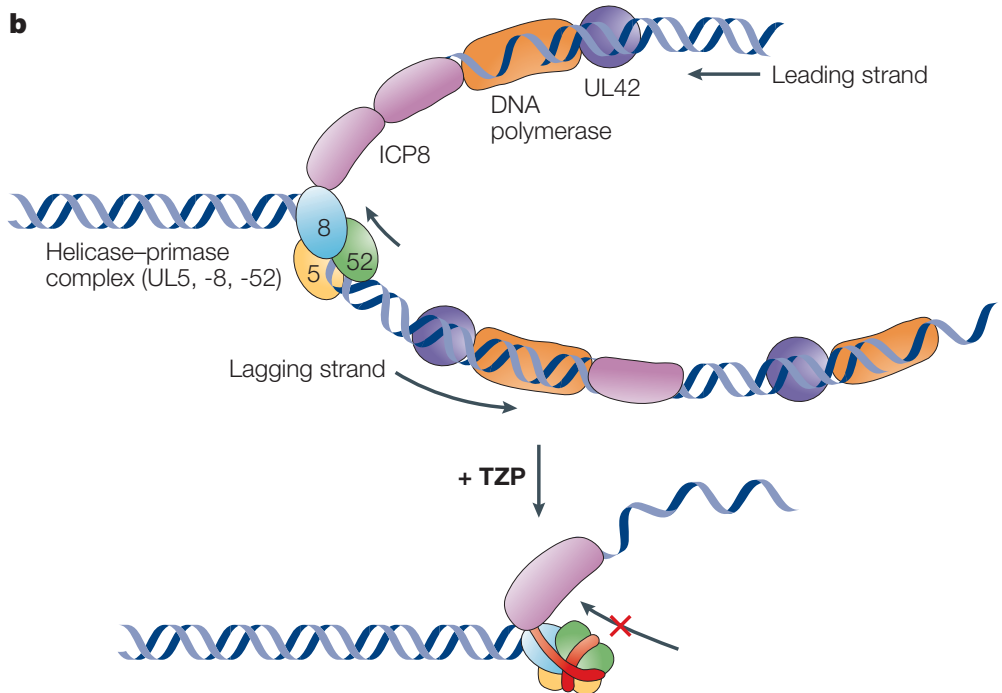

Figure 3 The mechanism of action of cidofovir and HSV helicase-primase complex inhibitors. a | The mechanism of antiviral action of cidofovir (HPMPC). As an acyclic nucleoside phosphonate, cidofovir is not dependent on activation by a virus-encoded enzyme for activity. Two phosphorylations are required for activity. Reproduced with permission from REF. 1 ( N Nature Rev. Drug Discov. (2002) Nature Publishing Group. b | The mechanism of inhibition of DNA synthesis by HSV helicase-primase complex inhibitors. The helicase-primase complex comprises the viral gene products UL5, -8 and -52 . This complex unwinds HSV DNA at the replication fork and primes DNA synthesis at both the lagging and the leading strands. The singlestranded-DNA-binding protein ICP8 binds to single-stranded template DNA. HSV DNA polymerase and its accessory protein UL42, promote leading- and lagging-strand DNA synthesis. The TZP (amino-thiazolylphenyl)-containing compounds (red band) enhance binding of the UL5 and UL52 subunits of the helicase-primase complex to both the leading- and the lagging-strand DNA, resulting in inhibition of helicase activity, primase activity and viral DNA synthesis. Modified with permission from REF. 15 @ Nature Medicine (2002) Nature Publishing Group.

contrast to BDCRB and TCRB, however, maribavir seems to target the UL97 protein kinase ${ }^{24}$. The UL97 gene product has recently been shown to be responsible for the release of HCMV nucleocapsids from the nucleus ${ }^{25}$, which means that maribavir targets a stage in the viral life cycle that follows viral DNA maturation and packaging. Preclinical pharmacokinetic and toxicological studies with maribavir have shown that it has a favourable safety profile and excellent oral bioavailability $^{26}$, and Phase I/II dose-escalation trials in HIV-infected men with asymptomatic HCMV shedding have indicated that maribavir is rapidly absorbed following oral dosing and achieved marked reductions in HCMV titre in semen ${ }^{27}$.

Primary HHV-6 infection, which generally occurs before the patient is 2 years old, is associated with exanthema subitum, and reactivation at a later age is frequent in immunocompromised individuals, particularly bone marrow or solid-organ transplant recipients. At present there is no standardized antiviral treatment for HHV-6 infections. The most potent compounds with the highest antiviral selectivity against HHV-6 are foscarnet, S2242 [2-amino-7-(1,3-dihydroxy-2propoxymethyl)purine] (which is the $N^{7}$-isomeric form of 6-deoxyganciclovir ${ }^{28}$ and has excellent activity against HHV-6), A-5021 and cidofovir. For HHV-7, which has not been proven to be linked to any disease, except possibly exanthema subitum, the most potent compounds proved to be S2242, cidofovir and foscarnet ${ }^{28}$.

\section{$\boldsymbol{\gamma}$-herpesvirus infections}

Among the $\gamma$-herpesviruses, Epstein-Barr virus (EBV) is responsible for infectious mononucleosis, Burkitt's lymphoma, nasopharyngeal carcinoma, lymphoproliferative syndrome, opportunistic B-cell lymphoma and oral hairy leukoplakia. Kaposi's sarcoma-associated virus (KSHV; which is also known as HHV-8) is associated with Kaposi's sarcoma, primary effusion lymphoma and Multicentric Castleman's disease.

Although several of the aforementioned licensed anti-herpetic drugs, such as acyclovir, BVDU and cidofovir, have proven to be effective against the in vitro replication of EBV and, in the case of cidofovir, its clinical manifestations (that is, oral hairy leukoplakia), none of these antiviral drugs has been licensed for the treatment of EBV infections. Recently, BDCRB and maribavir were shown to be active against $\mathrm{EBV}^{29}$.

For the treatment of HHV-8 infection or associated diseases, several drug candidates have been identified, including HPMPA [(S)-9-(3-hydroxy-2-phosphonylmethoxypropyl)adenine], cidofovir, S2242 and ganciclovir $^{28}$. Also, 4-oxo-dihydroquinolines such as PNU-183792 can inhibit HHV-8 replication due to a direct interaction with the HHV-8 DNA polymerase ${ }^{21}$. It has not yet been established whether any of the compounds that are effective against HHV-8 replication in cell culture in vitro will be efficacious in the treatment of HHV-8-associated diseases in vivo.

\section{Poxvirus infections}

The family of poxviridae includes orthopoxviruses (such as variola, vaccinia, cowpox, monkeypox and camelpox), parapoxviruses (such as orf) and mollusciviruses (molluscum contagiosum virus). The last natural case of smallpox, which is caused by variola virus, occurred in Somalia in 1977, and in 1980 the World Health Organization (WHO) declared smallpox to be officially eradicated. Since then, the only known stocks of variola virus have been held in Atlanta, USA, at the Centers for Disease Control (CDC), and in Koltsovo, Russia, in the State Research Centre of Virology and Biotechnology (VECTOR). If illegally 
preserved stocks of variola virus were ever used for biological and/or terrorist purposes in a highly mobile and susceptible population, the results could be catastrophic. In fact, variola virus could be considered an 'ideal' bioterrorist weapon for several reasons ${ }^{30}$ : it is highly transmissible by the aerosol route from infected to susceptible persons; the civilian populations of most countries contain a high proportion of susceptible (unvaccinated) persons; smallpox is associated with high morbidity and $~ 30 \%$ mortality; the initial diagnosis of a disease that has not been seen for 20 years would be difficult; and, at present, other than the vaccinia-based vaccine, which might be effective in the first few days post-infection, there is no formally approved drug for the treatment of smallpox.

The first antiviral compound to be used in the treatment and prophylaxis of smallpox, treatment of complications after smallpox vaccination and the treatment of eczema vaccinatum and vaccinia gangrenosa was methisazone ( $\mathrm{N}$-methylisatin 3-thiosemicarbazone $)^{31}$. Severe side effects were reported ${ }^{31}$ and follow-up studies $^{32}$ revealed that methisazone has in vitro activity against monkeypox virus and variola virus only at concentrations that are too high $\left(\sim 50 \mu \mathrm{g} \mathrm{ml}^{-1}\right)$ to be therapeutically meaningful.

Yet, several potential antiviral therapeutics have proven to be active against orthopoxvirus infections, both in cell culture ${ }^{33}$ and in animal model ${ }^{34}$, at concentrations and/or doses that could be used therapeutically. Several potential therapeutic strategies have been designed to target cellular enzymes. These enzymes include inosine $5^{\prime}$-monophosphate (IMP) dehydrogenase, which is responsible for the conversion of IMP to XMP (xanthosine $5^{\prime}$-monophosphate), an important step in the de novo biosynthesis of GTP; S-adenosylhomocysteine (SAH) hydrolase, the enzyme responsible for the hydrolysis of SAH, which is the product-inhibitor of S-adenosylmethionine (SAM)-dependent methylation reactions such as those involved in the maturation of viral mRNAs; oritidine 5'-phosphate (OMP) decarboxylase, the enzyme that is responsible for the conversion of OMP to UMP (uridine 5'-monophosphate), which is an important reaction in the de novo biosynthesis of UTP (uridine 5'-triphosphate); cytosine 5'-triphosphate (CTP) synthetase, which converts UTP to CTP; and viral enzymes such as the poxviral DNA polymerase ${ }^{35,36}$.

Several nucleoside and nucleotide analogues have been identified as potent anti-poxvirus agents. The nucleoside analogues include S2242 and 8-methyladenosine, whereas the nucleotide analogues include cidofovir, (S)-9-(3-hydroxy-2-phosphonylmethoxypropyl)-2,6diaminopurine (HPMPDAP) and (S)-6-(3-hydroxy-2phosphonylmethoxypropyl)oxy-2,4-diaminopyrimidine (HPMPO-DAPy). These compounds have been shown to be effective in various animal models of poxvirus infections $s^{37}$. Cidofovir can protect mice from a lethal respiratory infection with either vaccinia or cowpox, even when administered as a single systemic (intraperitoneal) or intranasal (aerosolized) dose $\mathrm{e}^{38}$, and is effective in the treatment of vaccinia virus infection in severe combined immune deficiency (SCID) mice.
In humans, anecdotal reports suggest that both topically and intravenously administered cidofovir can successfully treat recalcitrant molluscum contagiosum and orf infections in immunocompromised patients $\mathrm{s}^{38}$. Cidofovir is licensed for clinical use (in the treatment of CMV retinitis in AIDS patients) by intravenous injection. However, it could also be formulated for topical administration (for example, as a gel or cream) or for oral administration in prodrug form. The 1-Ohexadecyloxypropyl derivative (HDP-cidofovir), which has increased anti-poxvirus activity relative to cidofovir $^{39}$ owing to facilitated cellular uptake ${ }^{40}$, is under investigation as an oral prodrug.

Although the ultimate proof - activity against smallpox in humans - has not been (and, for obvious reasons, cannot be) provided, from the above discussion it can be inferred that cidofovir could be effective in the therapy and short-term prophylaxis of smallpox and related poxvirus infections (that is, monkeypox) in humans, as well as in the treatment of complications of vaccinia that can arise in immunocompromised patients who are inadvertently inoculated with the smallpox vaccine (vaccinia). A murine model that mimics progressive and disseminated vaccinia in humans has recently been developed ${ }^{41}$. In this model (athymic nude mice inoculated intracutaneously with vaccinia virus), systemic treatment with cidofovir when disseminated vaccinia developed caused the lesions to heal and regress. In most of the animals treated in this way the lesions completely (or almost completely) disappeared within 10-15 days of the start of therapy ${ }^{41}$. These observations have implications for the therapy of complications of smallpox vaccination.

\section{Hepadnavirus infections}

More than 350 million people worldwide are chronically infected with the hepadnavirus HBV, and complications of chronic hepatitis B infection, such as cirrhosis, hepatocellular carcinoma and end-stage liver disease, account for approximately 1 million deaths each year. The drugs that have been formally approved for the treatment of chronic hepatitis B are interferon (IFN)- $\alpha$, lamivudine (3TC) and adefovir dipivoxil [bis(POM)PMEA]. However, IFN treatment is compounded by side effects, such as influenza-like symptoms, anorexia and depression, which require dose adjustment or even discontinuation of therapy. In contrast with IFN, which must be given by parenteral administration, lamivudine can be administered orally and is well tolerated, but leads to resistance in up to $39 \%$ of patients after one year of therapy and $66 \%$ after four years of therapy.

Adefovir dipivoxil is the oral prodrug of adefovir (PMEA), which, after intracellular conversion to the diphosphate form, acts as a competitive inhibitor or alternative substrate for HBV reverse transcriptase and, when incorporated into the DNA, acts as a chain terminator, thereby preventing DNA elongation ${ }^{42}$ (FIG. 4). In patients with chronic HBV infection who were either positive $\mathrm{e}^{43}$ or negative $\mathrm{e}^{44}$ for hepatitis B e antigen, 48 weeks of treatment with a dose of adefovir dipivoxil as low as $10 \mathrm{mg} \mathrm{day}^{-1}$ resulted in significant improvement in 


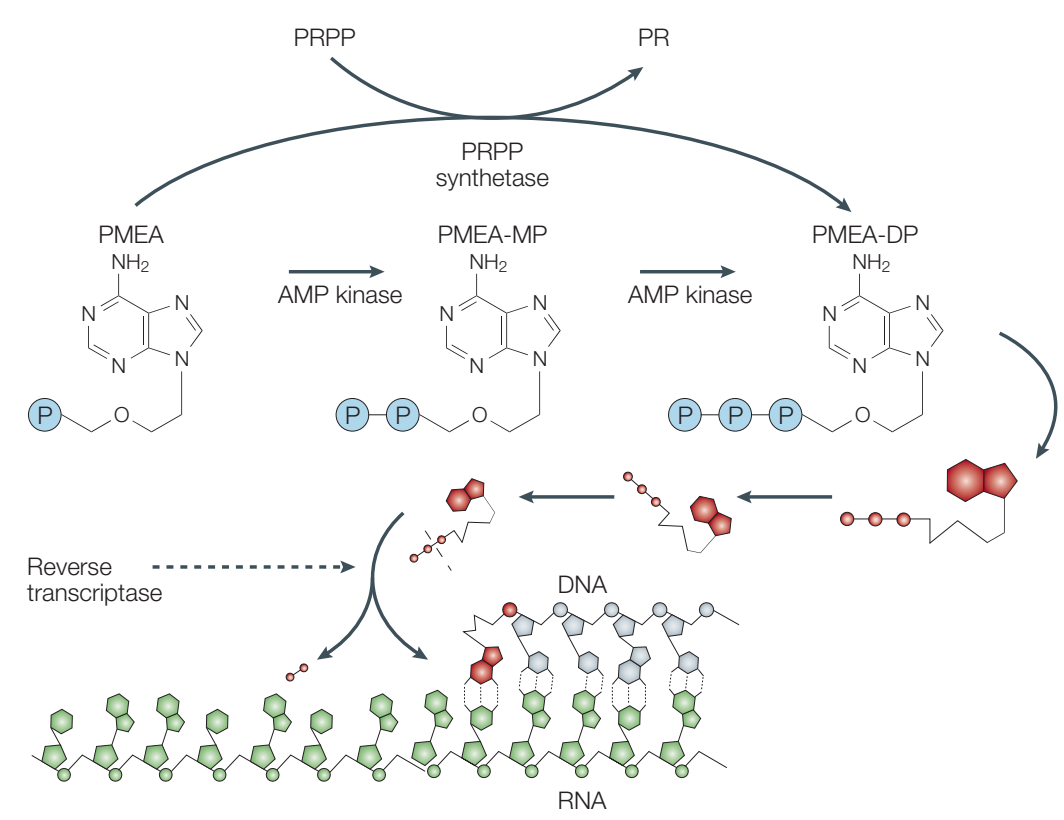

Figure 4 | The mechanism of action of adefovir (PMEA). After intracellular conversion to the diphosphate form, adefovir acts as a competitive inhibitor for HBV reverse transcriptase. When adefovir is incorporated into the DNA it acts as a chain terminator, thereby preventing DNA elongation. Reproduced with permission from REF.1 @ Nature Rev. Drug Discov. (2002) Nature Publishing Group. its $5^{\prime}$-triphosphate form, which, in the case of entecavir, would then compete with dGTP for the viral DNA polymerase. Intracellular entecavir 5'-triphosphate can be expected to accumulate at concentrations that are inhibitory to both wild-type and 3TC-resistant HBV DNA polymerase ${ }^{48}$.

Like entecavir, L-FMAU has proven to be a potent inhibitor of both DHBV and WHV replication in acutely infected ducks and chronically infected woodchucks, respectively ${ }^{49}$. At the highest dose administered $\left(10 \mathrm{mg} \mathrm{kg}^{-1}\right.$ day $\left.^{-1}\right)$, treatment with L-FMAU led to a reduction in the levels of covalently closed circular WHV DNA and, concomitantly with this, long-lasting suppression of viraemia after withdrawal of therapy ${ }^{49}$. Also, L-FMAU treatment followed by therapeutic vaccination to break immune tolerance has been advocated as a strategy to control chronic HBV infection in humans $s^{50}$.

The $\beta$-L-nucleoside analogues L-FMAU, $\mathrm{L}-\mathrm{dT}$ and L-dC must also be phosphorylated to their $5^{\prime}$-triphosphate form to interact with HBV DNA polymerase. In fact, L-dT and L-dC have been shown to be rapidly and extensively phosphorylated in both hepatoma cells and primary human hepatocytes ${ }^{51}$. The 3-phosphoglycerate kinase - a glycolytic enzyme that uses 1,3-bisphosphoglycerate as a phosphate donor to generate ATP during glycolysis - would have an important role in the phosphorylation of the L-nucleosides (diphosphates) to their $5^{\prime}$-triphosphate derivatives ${ }^{52}$.

It is noteworthy that adefovir dipivoxil — a drug that has now been approved worldwide for the treatment of chronic HBV infection - might be a promising adjunctive therapy against anthrax and other human diseases caused by pathogenic bacteria that secrete adenylyl cyclase toxins, such as Bordetella pertussis, Pseudomonas aeruginosa and Yersinia pestis ${ }^{53}$. Indeed, the active cellular metabolite of adefovir, adefovir diphosphate (PMEADP), was recently shown to inhibit the adenylyl cyclase activity of the oedema factor $\left(K_{\mathrm{i}}\right.$ of $27 \mathrm{nM}$ ), which is an important virulence factor in the pathogenesis of anthrax, especially during the early stages of the Bacillus anthracis infection where it contributes to both toxaemia and bacteraemia.

\section{Picornavirus infections}

The picornaviruses include the enteroviruses (such as poliovirus, coxsackieviruses $\mathrm{A}$ and $\mathrm{B}$, echovirus and hepatitis A virus) and rhinoviruses. Rhinoviruses are the main cause of the common cold, whereas enterovirus infections result in a myriad of disease syndromes, including viral meningitis and viral respiratory infections. Of these viruses, poliovirus has historically received most attention. After a successful worldwide vaccination campaign, the only countries in which polio still remains endemic are Niger, Nigeria, Egypt, India, Pakistan and Afghanistan. Hepatitis A can also be controlled sufficiently by the use of a killed virus vaccine. No vaccines are available for prevention of coxsackieviruses $\mathrm{A}$ and $\mathrm{B}$, echovirus and rhinovirus infections.

The compound that has been most extensively studied against both entero- and rhinoviruses is pleconaril. 


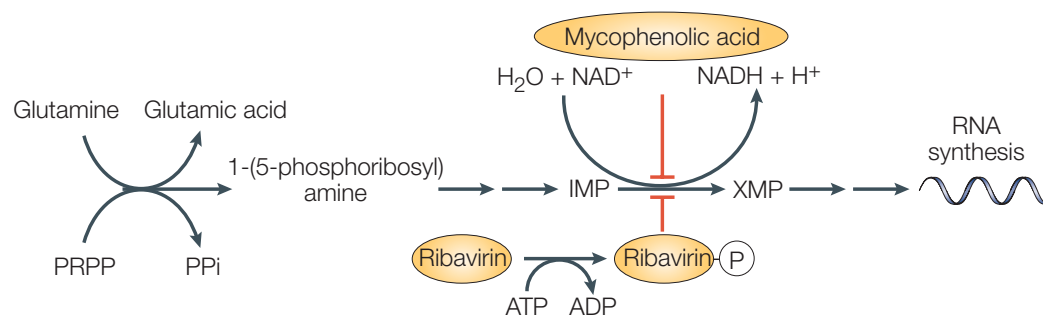

Figure 5 | The mechanism of action of ribavirin and mycophenolic acid, the active component of mycophenolate mofetil. Both these compounds block RNA synthesis by inhibiting the action of inosine $5^{\prime}$-monophosphate (IMP) dehydrogenase - this blocks the conversion of IMP to XMP (xanthosine 5'-monophosphate) and thereby stops GTP and, consequently, RNA synthesis.

This compound binds to a hydrophobic pocket beneath the 'canyon floor' of the VP1 capsid protein of picornaviruses $^{54}$, thereby 'freezing' the viral capsid and preventing its uncoating from the viral RNA genome. Pleconaril is orally bioavailable and achieves plasma concentrations greater than those that are required to inhibit $90 \%$ of clinical rhino- and enteroviral isolates in vitro. In addition, in the central nervous system (CNS) and nasal secretions the drug is present at concentrations several fold higher than in plasma - a highly desirable feature for an antiviral drug targeted towards viruses that are known to cause CNS and upper-respiratory-tract infections ${ }^{55}$. The clinical efficacy of pleconaril has been assessed in experimentally induced enterovirus (coxsackievirus A21) respiratory infections in adult volunteers ${ }^{56}$ and, on a compassionate basis $^{57}$, against potentially life-threatening enterovirus infections. When administered three-times daily, pleconaril reduced the duration and severity of picornavirus-associated viral respiratory illness in adolescents and adults ${ }^{58,59}$.

Coxsackie B viruses are thought to be the main aetiological agents of viral myocarditis, which is a common cause of idiopathic dilated cardiomyopathy - a severe pathological condition that often requires heart transplantation - and are therefore targets for chemotherapy. The immunosuppressive agent mycophenolate mofetil inhibits the development of coxsackie $\mathrm{B} 3$ virus-induced myocarditis in $\mathrm{C} 3 \mathrm{H}$ mice ${ }^{60}$. Mycophenolic acid (MPA), the active component of mycophenolate mofetil, is a potent inhibitor of IMP dehydrogenase and its antiviral and immunosuppressive effects can be attributed to this interaction, which reduces the supply of GTP (FIG. 5), and therefore, RNA synthesis. The beneficial effect of MPA cannot be ascribed to inhibition of viral replication, as the titre of infectious virus and viral RNA in heart tissue was increased in the mycophenolate-mofetil-treated animals compared with untreated animals ${ }^{60}$.

A more marked inhibitory effect on the development of coxsackie B3-virus-induced myocarditis, corroborated by a marked reduction in the virus titres in the heart, was obtained with the IFN inducers $\operatorname{poly}(\mathrm{I}) \cdot \operatorname{poly}(\mathrm{C})$ and $\operatorname{poly}(\mathrm{I}) \cdot \operatorname{poly}\left(\mathrm{C}_{12} \mathrm{U}\right)$ (also known as ampligen) and, to a lesser extent, with IFN- $\alpha 2 \mathrm{~b}$ and pegylated IFN- $\alpha 2 b^{61}$. Even when the start of treatment with poly $(\mathrm{I}) \cdot \operatorname{poly}\left(\mathrm{C}_{12} \mathrm{U}\right)$ was delayed until two days post-infection, when lesions had already appeared in the untreated control animals, a marked protective effect on the development of viral myocarditis (assessed six days post-infection) was observed. A combination of an inhibitor of viral replication (such as ampligen) and an immunosuppressant (such as mycophenolate mofetil) could be an ideal treatment strategy for viral myocarditis. How to implement such a treatment regimen in the clinical setting remains to be addressed.

\section{Flavivirus infections}

The genus Flavivirus contains more than 70 species, many of which cause disease in humans. Severe flavivirus infections are generally characterized by encephalitis or haemorrhagic symptoms. Mortality rates vary from $1-2 \%$ (in the cases of Central European encephalitis virus) to $30-40 \%$ (in the case of Japanese encephalitis virus and tick-borne encephalitis virus, which was previously known as Russian Spring and Summer encephalitis virus). Other important flaviviruses include yellow fever virus, dengue virus, West Nile virus, St Louis encephalitis virus and Murray Valley encephalitis virus. Although feared as a possible bioterrorist weapon, the development of tick-borne flaviviruses as bioweapons might not be practical, as large numbers of infected ticks would be required and it would be difficult to arrange for them to be infected and ready to feed when delivered as weapons ${ }^{62}$.

The prospects for the therapy of flavivirus infections are not encouraging ${ }^{63}$. There are some compounds 6-azauridine, cyclopentenylcytosine, MPA and pyrazofurin — that have activity against West Nile virus ${ }^{64}$. Ribavirin has only weak activity against flaviviruses. The use of IFN and IFN inducers might be possible, but, in general, this treatment should be started before or very shortly after infection to have any beneficial effect. An experimental flavivirus encephalitis model has been developed based on infection of hamsters with the murine Modoc virus ${ }^{65}$; during the acute phase, the infection is associated with flaccid paralysis and the neurological sequelae that can develop are similar to those that have been observed in survivors of Japanese encephalitis ${ }^{65}$. This model should be suitable for the evaluation of anti-flavivirus therapies. At present, IFN- $\alpha 2 b$, whether pegylated or not, and IFN inducers (poly(I)·poly (C) and ampligen) offer the greatest potential for activity in this model, as they have been shown to significantly delay virus-induced morbidity (paralysis) and mortality (due to progressive encephalitis) in a related model with Modoc virus in SCID mice ${ }^{66}$. It is noteworthy that ribavirin did not provide any beneficial effect in this model, whether given alone or in combination with IFN.

\section{Arenavirus infections}

Of the 23 arenavirus species that are known, five are associated with viral haemorrhagic fevers - Lassa, Junin, Machupo, Guanarito and Sabia ${ }^{67}$. These viruses are included in the CDC Category A Pathogen List. It is gratifying to note that, as demonstrated with Tacaribe virus and an attenuated Junin virus strain, in vitro 


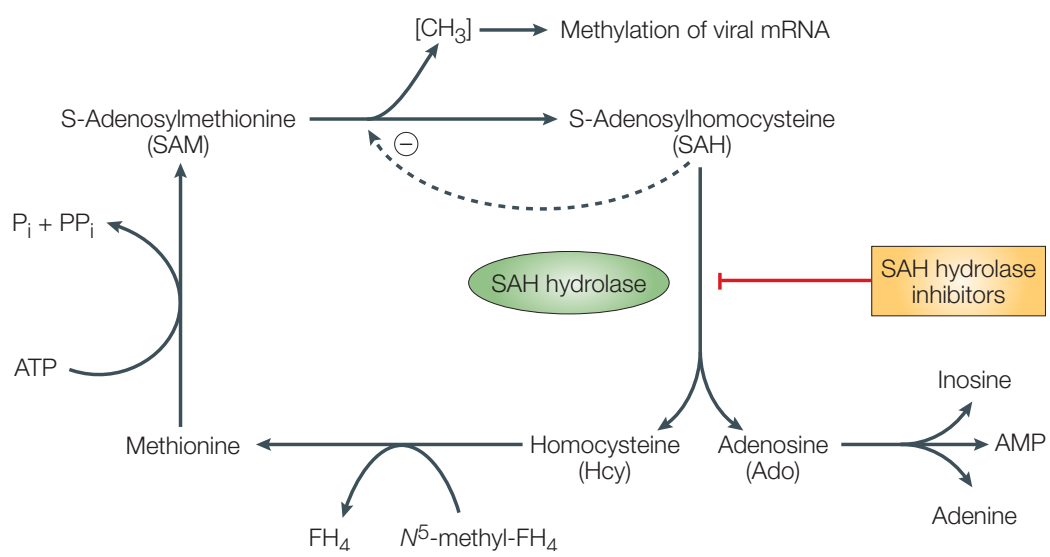

Figure 6 | The mechanism of action of adenosine analogues such as 3-deazaneplanocin A. These compounds inhibit the action of S-adenosylhomocysteine (SAH) hydrolase, which hydrolyses SAH, the product-inhibitor of S-adenosylmethionine (SAM)-dependent methylation reactions. Inhibiting these reactions can affect transcription.

arenavirus replication is susceptible to several compounds, including adenosine analogues (for example, SAH hydrolase inhibitors such as 3-deazaneplanocin A), cytidine analogues (for example, cyclopentenyl cytosine), guanosine analogues (for example, IMP-dehydrogenase inhibitors such as ribavirin) and sulphated polysaccharides (for example, dextran sulphate) ${ }^{68}$.

Ribavirin has proven to be effective in the postexposure prophylaxis and therapy of experimental arenavirus infections in animal models, and anecdotal reports suggest that it might also be effective in the treatment of arenavirus infections (Machupo and Sabia viruses) in humans ${ }^{67}$. The most convincing evidence for the efficacy of ribavirin was obtained in the case of Lassa fever, where it was shown to reduce the case-fatality rate, irrespective of the time point in the illness at which treatment was started ${ }^{69}$.

\section{Bunya- and togavirus infections}

Several togaviruses and bunyaviruses have been described as potential bioterrorism agents - for example, the togaviruses Venezuelan equine encephalitis virus, Eastern equine encephalitis virus and Western equine encephalitis virus, and the bunyaviruses Rift Valley fever virus, Crimean-Congo haemorrhagic fever virus and hantaviruses such as Hantaan virus ${ }^{70}$. However, hantaviruses are unlikely candidates for biological warfare purposes as they are difficult to isolate (and grow) in cell culture, they are not transmitted between humans and there is no evidence that they are infectious by aerosol ${ }^{71}$. Crimean-Congo haemorrhagic fever virus, however, can be readily cultivated, is highly infectious (although so far there is no evidence that it is infectious in aerosol form) and is easily transmitted between humans, giving rise to local epidemics and even nosocomial infections. The case-fatality rate associated with Crimean-Congo haemorrhagic virus is $\sim 30 \%$, which is higher than that of most other viral haemorrhagic fevers ${ }^{71}$.

Bunyaviruses are generally sensitive to ribavirin, and this has also been demonstrated in experimental animal models ${ }^{70}$. IFN and IFN inducers have also proved effective in the treatment of experimental bunyavirus infection, if, as is usual for these compounds, they are administered as early as possible after infection. As for flavivirus infections, ribavirin is of no use in the treatment of togavirus infections. For these infections, IFN (whether pegylated or not) and IFN inducers (such as ampligen) are the recommended therapeutic agents ${ }^{70}$.

\section{Rhabdo- and filovirus infections}

Rhabdoviruses (such as Rabies virus) and filoviruses (such as Ebola and Marburg viruses) are among the most deadly viruses to infect humans. Rabies is almost invariably fatal, as illustrated by a recent case report $^{72}$; however, rabies can be contained by repeated administration of specific immunoglobulin and the use of a killed rabies vaccine as soon as possible after the infection has taken place. No vaccine is available for either Ebola or Marburg infections and these viruses are classified as Category A Pathogens. Filoviruses are highly infectious by the airborne route, but can also be transmitted between humans through direct contact with virus-containing body fluids. Although filoviruses could be more difficult for potential bioterrorists to acquire than other biological agents such as B. anthracis, their reputation for causing deadly disease might make the effort required seem worthwhile ${ }^{73}$.

Specific immunoglobulin or IFN- $\alpha 2 b$ are of only limited value in the treatment of experimental Ebola virus infections - for example, rhesus macaques that were treated from the day of infection with Ebola (Zaire) virus experienced a delay of only one day in the onset of illness, viraemia and death ${ }^{74}$. No antiviral drugs that are currently in clinical use, including ribavirin, provide any protection against filoviruses ${ }^{73}$. The most promising therapeutic strategy might be based on the use of SAH hydrolase inhibitors such as 3-deazaneplanocin A. As already described, SAH hydrolase inhibitors interfere with SAM-dependent methylation reactions (FIG. 6) such as those involved in the 'capping' of viral mRNA.

Some viruses, including rhabdoviruses such as vesicular stomatitis virus (VSV), rely on mRNA 'capping', as they are particularly sensitive to inhibition by $\mathrm{SAH}$ hydrolase inhibitors ${ }^{75}$. Biochemically, filoviruses are similar to rhabdoviruses — both require $5^{\prime}$-capping of the mRNAs - and, therefore, it could be logically deduced that SAH hydrolase inhibitors such as neplanocin A and 3-deazaneplanocin A, which are highly active both in vitro and in vivo against $\mathrm{VSV}^{76}$, would also be effective in the treatment of Ebola virus infections.

In fact, when administered as a single dose of $1 \mathrm{mg} \mathrm{kg}^{-1}$ on the first or second day after an Ebola Zaire virus infection in mice, 3-deazaneplanocin A reduced peak viraemia by more than 1,000-fold compared with mock-treated controls, and most or all the animals survived ${ }^{77}$. This protective effect was accompanied, and probably mediated, by the production of high 
concentrations of IFN- $\alpha$ in the Ebola virus-infected mice $^{78}$. It can be hypothesized that, by blocking the 5 -capping of the nascent (+)RNA viral strands, 3-deazaneplanocin A prevented the dissociation of these strands from the viral (-)RNA template, thereby leading to an accumulation of replicative intermediates. These replicative intermediates - composed of dsRNA stretches - could then induce the production of high concentrations of IFN ${ }^{79}$.

\section{Hepacivirus infections}

It is estimated that more than 170 million people worldwide are infected with the hepacivirus hepatitis $\mathrm{C}$ virus (HCV), which is a bloodborne virus that is often sub-clinical but which, in up to $85 \%$ of cases, leads to a chronic infection that ultimately results in liver fibrosis (cirrhosis), hepatic failure or hepatocellular carcinoma. HCV infection is the most common cause of hepatocellular carcinoma and the main reason for liver transplantation among adults in western countries. The development of effective anti-HCV therapeutics continues to be a daunting challenge owing to the absence of adequate animal models and cell-culture systems for evaluating propagation of the virus and its inhibitors ${ }^{80}$.

At present, the recommended (and approved) therapy for chronic HCV infections consists of pegylated IFN$\alpha 2 \mathrm{a}$ combined with ribavirin. This therapy is associated with a sustained viral response rate of $\sim 50 \%$ among patients infected with HCV genotype 1 and of $\sim 80 \%$ in patients infected with HCV of another genotype. Treatment with pegylated IFN- $\alpha 2 \mathrm{a}$ and ribavirin can be individualized by genotype ${ }^{81}$. Patients that are infected with HCV genotype 1 require treatment for 48 weeks ${ }^{81}$ (or longer ${ }^{82}$, whereas patients that are infected with HCV genotypes 2 or 3 can be treated for 24 weeks. In addition, for the latter group, the dose of ribavirin can be reduced (from 1,000 or 1,200 $\mathrm{mg} \mathrm{day}^{-1}$ to 800 or even $\left.600 \mathrm{mg} \mathrm{day}^{-1}\right)$. Lowering the duration of therapy with a combination of pegylated IFN- $\alpha$ and ribavirin is not a trivial issue owing to both the cost of therapy and its associated toxicities (flu-like syndrome, depression and alterations in red blood cell counts).

Although IFN is generally an immunomodulatory agent and ribavirin is an antiviral agent, when the two agents are used in combination against hepatitis $\mathrm{C}$ they appear to act the other way around. Recent work has focused on the development of compounds that interfere with the non-structural (NS) protein-associated NTPase/helicase, serine protease and RNA-dependent RNA polymerase (RNA replicase) activities of HCV. Halogenated benzimidazoles and benzotriazoles have been proposed to be inhibitors of the HCV NTPase/ helicase ${ }^{83}$ but whether they also inhibit HCV replication remains to be determined. Recently, a NS3 protease inhibitor (BILN 2061) was reported to reduce the plasma concentrations of HCV RNA when administered orally for 2 days to patients who were infected with HCV genotype 1, thereby providing proof-ofefficacy for the use of HCV NS3 protease inhibitors in humans ${ }^{84}$.
An attractive approach for the development of $\mathrm{HCV}$ inhibitors is to target the NS5B RNA-dependent RNA polymerase (RdRp). The impetus for such an approach comes from the fact that VP 32947 or 3-[((2-dipropylamino)ethyl)thio]-5H-1,2,4-triazino(5,6-b)indole was found to suppress the replication of bovine viral diarrhoea virus (BVDV) through an inhibitory effect on the NS5B RdRp ${ }^{85}$. Infections with this pestivirus have an economic impact, but can also be considered as a surrogate virus for HCV. Other compounds that have been identified as highly selective inhibitors of BVDV replication owing to a specific inhibitory effect on the BVDV RNA replicase are compound 1453 (REF. 86) and compound ' 22 ' (REF. 87). Although these compounds, in their own right, could be pursued for the treatment of pestivirus infections in domesticated livestock, they could also be model compounds for the development of non-nucleoside HCV RdRp inhibitors. As nonnucleoside RdRp inhibitors such as compound '22' are active at nanomolar concentrations ${ }^{87}$, they seem, at first glance, much more potent than the (ribo)nucleoside analogues, such as $N^{4}$-hydroxycytidine ${ }^{88}$, that have been reported to block the replication of BVDV and HCV.

\section{Orthomyxovirus infections}

Of the orthomyxoviruses, influenza A and influenza B viruses cause epidemics in humans. Influenza A viruses, which have been isolated from a wide variety of avian and mammalian species, can cause widespread human epidemics or pandemics with high mortality rates because these viruses are readily and rapidly transmitted between humans by the aerosol route. Whereas influenza B virus only undergoes antigenic drift based on relatively minor changes (transition and/or transversion mutations) in the viral surface glycoproteins haemagglutinin (HA) and neuraminidase (NA), influenza A virus is prone to both antigenic drift and antigenic shift, the latter resulting from major antigenic changes owing to reassortment of genomic fragments between influenza viruses of different animal species.

The high virulence of some influenza A virus strains, such as H5N1, which emerged in Hong Kong in 1997, and the fact that lethal influenza A viruses can be generated in the laboratory by reverse genetics, have accentuated the fear of influenza A viruses being used as bioterrorist weapons ${ }^{89}$. Additionally, highly pathogenic avian influenza A viruses — for example, subtype H7N7 - that are responsible for fowl plague in poultry, can be transmitted to people who handle infected poultry and be further transmitted from person to person ${ }^{90}$; a fatal course of pneumonia in association with acute respiratory distress syndrome has been noted in an individual infected with the avian H7N7 virus ${ }^{91}$.

For many years, amantadine and rimantadine have been used for the prophylaxis and therapy of influenza A virus infections, but they have not gained wide acceptance for three reasons. First, these agents do not have activity against influenza $B$ viruses, as these viruses lack the matrix protein $\mathrm{M} 2$ that determines the anti-influenzavirus activity of amantadine and rimantadine; second, the prospect of rapid emergence of drug-resistant virus 


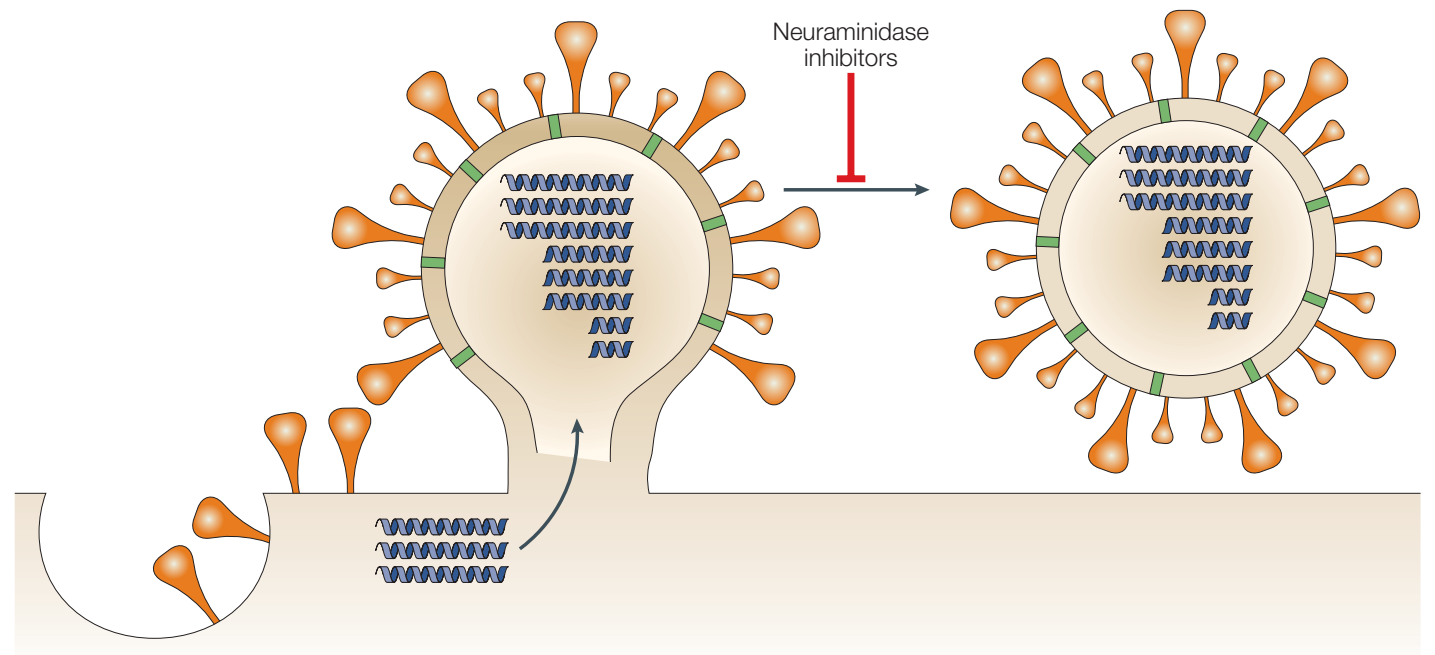

Figure 7 | Schematic showing the mechanism of action of neuraminidase (NA) inhibitors, which target influenza viruses. NA facilitates the release of virus particles from infected cells by cleaving a sialic acid residue from the cell-surface glycoprotein. By blocking this reaction, NA inhibitors prevent the release of virus.

mutants; and third, possible side effects affecting the CNS, which have been particularly documented for amantadine.

Given their specificity for influenza virus strains that are already circulating, influenza vaccines are likely to be of limited value against a newly emerging influenza strain, whether occurring naturally or as a bioterrorist weapon. In this case, antiviral drugs that are directed at functions shared by as many influenza strains as possible would constitute the best line of defence ${ }^{89}$. The NA inhibitors zanamivir ${ }^{92}$ and oseltamivir ${ }^{93}$ meet these requirements. These compounds prevent the removal of the sialic acid ( $\mathrm{N}$-acetylneuraminic acid) residue from the glycopeptide receptor (FIG. 7) by the viral NA, which would otherwise allow the virus particles to be released from the infected cell (and spread to neighbouring cells). Both have been licensed for the treatment and prophylaxis of influenza virus infections, and it would be advisable to have stockpiles of these compounds (particularly oseltamivir because it can be conveniently administered as capsules) to be used in case of an influenza virus outbreak or attack.

\section{Paramyxovirus infections}

The paramyxoviruses include parainfluenza 1,2,3, 4a and $4 \mathrm{~b}$, Sendai virus, mumps virus, measles virus, Hendra and Nipah viruses, and the pneumoviruses respiratory syncytial virus (RSV) and human metapneumovirus (hMPV). Parainfluenza has been little studied from either a preventative or curative viewpoint. Mumps and measles, like rubella, are now sufficiently contained by vaccination, which makes Nipah virus (and the related Hendra virus), RSV and hMPV the paramyxoviruses for which antiviral approaches are required.

Nipah virus was isolated during an outbreak of viral encephalitis in Malaysia 5 years ago and has many characteristics that would make it a potential bioterrorist weapon ${ }^{94}$. There is no specific antiviral treatment for Nipah virus infections.
hMPV was first isolated in 2001 from young children with respiratory-tract disease ${ }^{95}$. The clinical symptoms are similar to those caused by RSV, and range from upper-respiratory-tract disease to severe bronchiolitis and pneumonia. hMPV is similar to RSV in that infection usually occurs during the winter months and is common in young children, elderly people and immunocompromised individuals. In a study carried out on hospitalized patients with respiratory-tract illness, hMPV was the second-most-detected viral pathogen (RSV being the first) during two successive winter seasons ${ }^{96}$. There is no specific antiviral treatment for hMPV infection.

A significant number of patients who are diagnosed with influenza-like illness harbour RSV and, as influenza and RSV infections occur at approximately the same time, there is a need to distinguish between the two to prescribe specific antiviral treatment ${ }^{97}$. As mentioned above, specific treatment for influenza consists of the NA inhibitors (zanamivir and oseltamivir), whereas for RSV infections the only approved therapy is aerosol administration of ribavirin. In practice, however, ribavirin is rarely used owing to the technical burden of delivery by aerosol inhalation. Attempts have been made to develop RSV inhibitors that target the viral fusion (F) protein and therefore block viruscell fusion and syncytium formation. An example is $4,4^{\prime}$ - bis- [4,6-bis-(3- (bis-car ba moylmethylsulphamoyl)-phenylamino )- $(1,3,5)$ triazin-2 ylamino]-biphenyl-2',2'-disulphonic acid (RFI-641), which has proved to be efficacious when administered prophylactically (or up to 24 hours post-infection) by the intranasal route in mice, cotton rats and African green monkeys intranasally infected with RSV ${ }^{98}$.

\section{Coronavirus infections}

In the past, human coronavirus infections, such as infection by $229 \mathrm{E}$ virus, were not considered sufficiently serious to be controlled by either vaccination or 
specific antiviral therapy. This has now changed markedly with the emergence of severe acute respiratory syndrome (SARS), which has been unequivocally associated with a newly discovered coronavirus SARS-associated coronavirus (SARS-CoV) ${ }^{99-104}$. The disease is mainly characterized by influenza-like symptoms, high fever, myalgia, dyspnea, lymphopoenia and lung infiltrates (pneumonia) leading to acute breathing problems, with an overall mortality rate of about $10 \%$ (in the elderly this can be as high as 50\%).

The genome structure, life cycle and phylogenetic relationships of SARS-CoV have been addressed previously $^{105}$. There are several proteins encoded by the SARS-CoV genome that could be considered targets for chemotherapeutic intervention: the spike (S) protein, the coronavirus main proteinase (3CLpro), the NTPase/helicase, the RNA-dependent RNA polymerase and, possibly, other viral-protein-mediated processes.

The coronavirus $\mathrm{S}$ protein mediates infection of permissive cells through interaction of its $S 1$ domain with angiotensin-converting enzyme 2 (ACE2), which is a functional receptor for SARS-CoV ${ }^{106}$. A 193-aminoacid fragment of the $S$ protein (corresponding to residues 318-510) binds ACE2 more efficiently than the full S1 domain and, in fact, the 193-residue fragment blocks S-protein-mediated infection with an $\mathrm{IC}_{50}$ of $<10 \mathrm{nM}$ (the $\mathrm{IC}_{50}$ of the full S1 domain is $\left.\sim 50 \mathrm{nM}\right)^{107}$. Also, human monoclonal antibodies to the $\mathrm{S} 1$ protein block the association of SARS-CoV with ACE2, indicating that the ACE2-binding site of S1 could be a target for drug development ${ }^{108}$. The first small-molecularweight inhibitor that was found to interact with the ACE2 active catalytic site, (S,S)-2-[1-carboxy-2-(3-(3,5dichloro-benzyl)-3H-imidazol-4-yl)-ethylamino]-4methyl-pentanoic acid (MLN-4760), has already been described ${ }^{109}$. Whether MLN-4760 inhibits SARS-CoV infection remains to be ascertained.

The coronavirus main proteinase, Mpro, also known as 3CLpro, is a target for the design of antiSARS-CoV drugs ${ }^{110}$. It was proposed that compounds such as AG7088, which have proven to be active against the rhinovirus $3 \mathrm{C}$ proteinase, could be modified to make them active against coronaviruses ${ }^{110}$. A first modification of AG7088 that removed the methylene group of the $p$-fluorophenylalanine residue created KZ7088. KZ7088 has been modelled into the structure of the SARS-CoV 3Clpro protein ${ }^{111}$, and further work in this area could advance structure-based drug design against SARS $^{112}$. Another potential target for the development of anti-SARS agents is the SARS-CoV-associated NTPase/helicase ${ }^{113}$.

The SARS-CoV RNA-dependent RNA polymerase is also a potential target for anti-SARS therapy ${ }^{114}$. This enzyme does not contain a hydrophobic pocket for nonnucleoside inhibitors such as those that have proven active against HCV polymerase or HIV-1 reverse transcriptase $^{114}$. Of the many nucleoside analogues that are expected to target the SARS-CoV RNA polymerase and for which efficacy has been determined, only $N^{4}$-hydroxycytidine - incidentally, the same compound that has been accredited with anti-HCV activity ${ }^{73}$ - showed activity, albeit at a low level ( $\mathrm{EC}_{50}$ of $10 \mu \mathrm{M}$; selectivity index of $\geq 10$ ), against SARS-CoV replication in cell culture $^{115}$.

In addition to $\mathrm{N}^{4}$-hydroxycytidine, some calpain inhibitors ( $N$-(4-fluorophenylsulphonyl)-L-valyl-Lleucinal) inhibit SARS-CoV replication $\left(\mathrm{EC}_{50}\right.$ of $1 \mu \mathrm{M}$; selectivity index of $\geq 100)^{115}$. The target of the calpain inhibitors remains to be elucidated. Inhibitory effects on SARS-CoV (again with selectivity indexes of up to $\sim 100$ and $\mathrm{EC}_{50}$ values as low as $1 \mu \mathrm{g} \mathrm{ml}^{-1}$ ), have been observed for a variety of compounds, including vancomycin, eremomycin and teicoplanin aglycon derivatives ${ }^{116}$, and mannose-specific plant lectins, derived from Galanthus nivalis (snowdrop), Hippeastrum hybrid (amaryllis) ${ }^{117}$ or Allium porrum (leek) ${ }^{118}$, which might all owe their antiviral activity to an interaction with components of the viral entry machinery. Glycyrrhizin has also been shown to inhibit the replication of SARS-CoV ${ }^{119}$, but only at concentrations $\left(\mathrm{EC}_{50}\right.$ of $\left.300-600 \mu \mathrm{g} \mathrm{ml}^{-1}\right)$ that could not be achieved in the target tissue or organs.

An effective agent, at least for the prophylaxis and early post-exposure management of SARS, would seem to be human IFN, either $\alpha, \beta$ or $\gamma^{120}$. Pegylated IFN- $\alpha$ was recently shown to reduce viral replication and excretion, viral antigen expression by type 1 pneumocytes and the attendant pulmonary damage in cynomolgus macaques that were infected experimentally with SARS-CoV ${ }^{121}$. These preliminary results warrant further studies with pegylated IFN- $\alpha$, which is commercially available, in the prophylactic or early post-exposure treatment of SARS should it re-emerge.

\section{Reovirus infections}

Rotavirus, which is associated with worldwide epidemics of viral gastrointestinal infections, is the most clinically important of the reoviruses. Although several attempts have been, and are still being, made to develop an effective vaccine for rotavirus infections, the current treatment for this infectious diarrhoea is mainly based on the administration of fluids (physiological saline) to prevent dehydration. Yet, it should be pointed out that SAH hydrolase inhibitors such as 3-deazaneplanocin A (see above) offer great promise for the treatment of reo(or rota-) virus infections. In cell culture ${ }^{76}, 3$-deazaneplanocin A was found to inhibit rotavirus replication at an $\mathrm{EC}_{50}$ of $0.04 \mu \mathrm{g} \mathrm{ml}^{-1}$ and a selectivity index of 10,000 .

\section{Retrovirus infections}

Since the identification of HIV as the causative agent of AIDS more than 20 years ago, so many efforts have been made to keep this disease under control that 19 compounds have been formally approved as anti-HIV drugs, and they can be used in a variety of combinations ${ }^{122}$. They can be divided into five categories: the nucleoside reverse transcriptase inhibitors (NRTIs), such as zidovudine, didanosine, zalcitabine, stavudine, lamivudine, abacavir and emtricitabine; the nucleotide reverse transcriptase inhibitors (NtRTIs), such as tenofovir disoproxil fumarate; the non-nucleoside reverse transcriptase inhibitors (NNRTIs), such as nevirapine, delavirdine and efavirenz; the protease inhibitors (PIs), 


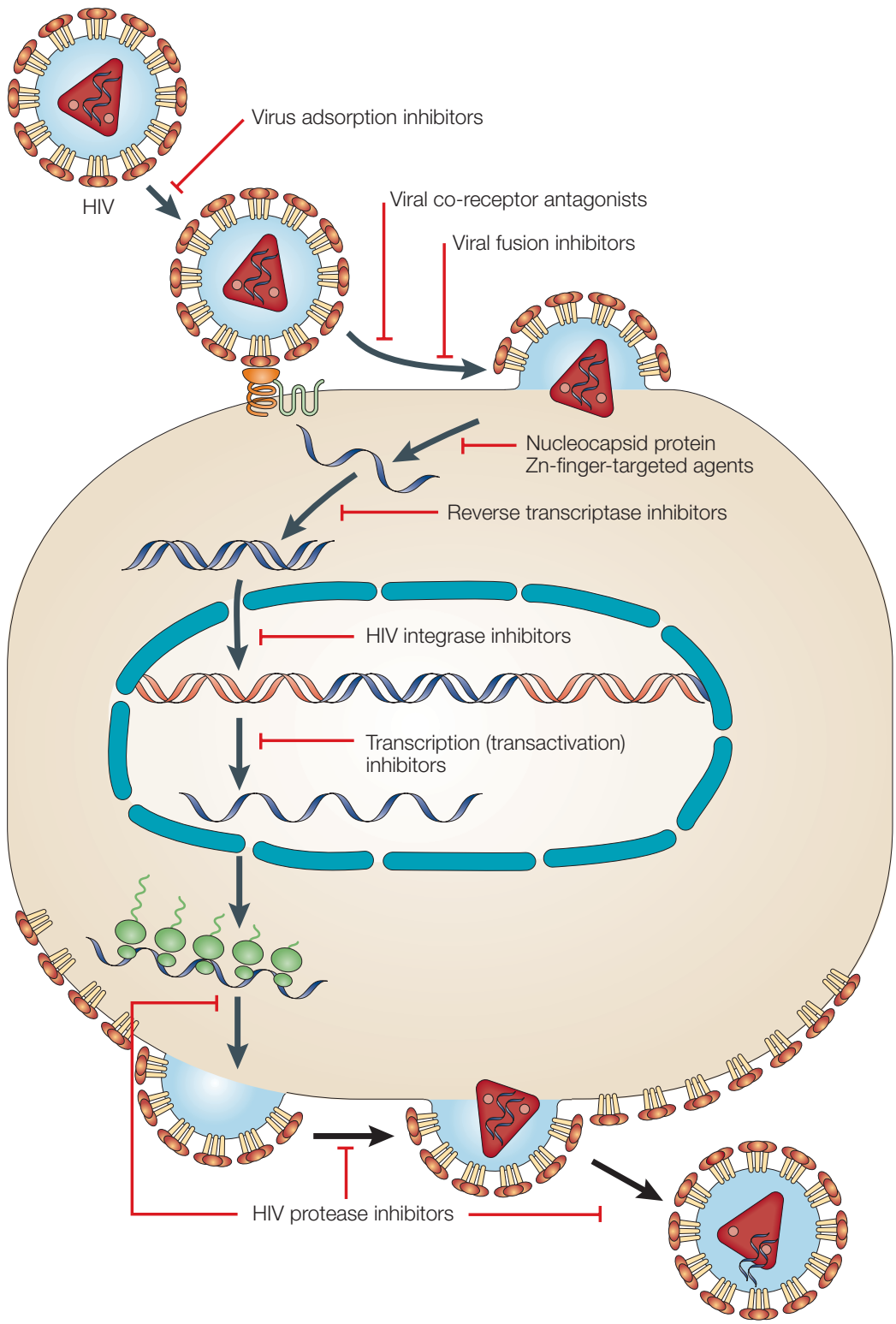

Figure 8 | Schematic representation of the HIV life cycle, depicting the targets for anti-HIV agents. So far, 19 compounds have been licensed for use in HIV therapy. The five main drug categories are nucleoside reverse transcriptase inhibitors, nucleotide reverse transcriptase inhibitors, non-nucleoside reverse transcriptase inhibitors, protease inhibitors and fusion inhibitors. New agents include viral adsorption inhibitors and co-receptor antagonists. Modified with permission from REF.1 () Nature Rev. Drug Discov. (2002) Nature Publishing Group.

such as saquinavir, ritonavir, indinavir, nelfinavir, amprenavir, lopinavir and atazanavir; and enfuvirtide, which is a fusion inhibitor (FI).

In addition, various new anti-HIV agents have been described that are presently under clinical or preclinical development ${ }^{123}$. These new agents target either the same viral proteins as the 'old' ones - reverse transcriptase, protease or the gp41 envelope glycoprotein — which mediate fusion, or 'new', yet to be therapeutically validated, viral processes such as viral adsorption (mediated by the gp120 glycoprotein), co-receptor (CXCR4 or CCR5) usage, proviral DNA integration or transcription transactivation (FIG. 8).
Several noteworthy compounds have proceeded through clinical trials ${ }^{124}$ including the following compounds. The bicyclam AMD3100 (REF. 125), which specifically targets CXCR4, the co-receptor that is used by T-lymphotropic (or X4) HIV strains to enter cells, and SCH-C (SCH 351125), which specifically targets CCR5, the co-receptor used by macrophage (M)-tropic (or R5) HIV strains to enter cells. New NRTIs such as $\beta$-D-2', $3^{\prime}$-didehydro-2', $3^{\prime}$-dideoxy-5-fluorocytidine (which is marketed as Reverset ${ }^{\mathrm{TM}}$ ) and amdoxovir (which is also known as DAPD; (-)- $\beta$-D-2,6-diaminopurine dioxolane), which are active against HIV isolates with resistance to other NRTIs such as zidovudine and lamivudine. New NNRTIs such as capravirine and etravirine, which are effective against HIV-1 strains carrying the $\mathrm{K} 103 \mathrm{~N}$ and $\mathrm{Y} 181 \mathrm{C}$ mutations that make them resistant to the 'classical' NNRTIs (nevirapine and efavirenz). S-1360, a diketo-acid derivative targeted at the integrase-mediated strand-transfer reaction and the first integrase inhibitor to reach clinical studies. Finally, tipranavir (PNU-140690), which is the first nonpeptidomimetic inhibitor of the HIV protease to be brought to the clinic and which is expected to retain activity against HIV-1 isolates that have developed resistance to the 'classical' peptidomimetic PIs.

Several other therapeutic strategies that are still at the preclinical stage are being pursued for the chemotherapy of HIV infections ${ }^{124}$. These include the following strategies. Downmodulation of CD4 which is the main cellular receptor used by HIV to bind to its target cells - by cyclotriazadisulphonamides (CADAs). The use of compounds that specifically bind to the viral envelope glycoprotein gp 120, such as BMS-378806 [4-benzoyl-1-(4-methoxy-1H-pyrrolo(2,3-b)pyridin-3-yl)oxoacetyl-2-( $R)$-methylpiperazine], and which thereby block interaction of gp120 with CD4. Using plant lectins derived from snowdrop agglutinin (GNA), amaryllis lectin (HHA) and aglycons of the glycopeptide antibiotics vancomycin, teicoplanin and eremomycin, which specifically interact with gp120. Developing pyranodipyrimidine inhibitors of HIV integrase, such as V-165, that inhibit integration in a manner that is different from the diketo-acid derivatives (such as S-1360) in that they do not show cross-resistance with the diketo-acid derivatives; and finally, two new classes of compounds ( $N$-aminoimidazole derivatives (NAIMS) and pyridine oxide derivatives), which seem to inhibit a postintegration, transcription transactivation event, the exact nature of which remains to be elucidated.

Recently, a new class of anti-HIV compounds called maturation inhibitors were identified ${ }^{126}$. PA-457 [3-O( $3^{\prime}, 3^{\prime}$-dimethylsuccinyl) betulinic acid] disrupts a late step in HIV-1 Gag processing that involves conversion of the capsid precursor (p25) to mature capsid protein (p24). Virions released from PA-457-treated cultures are no longer infectious, and resistance mutations have been identified in the p25 to p24 cleavage site ${ }^{126}$. Further studies are required to assess whether PA-456 (and similar compounds) have therapeutic potential for HIV infections. 


\section{Conclusion}

At present, 37 chemicals, plus IFN- $\alpha$ in both pegylated and unpegylated forms, have been formally approved for the treatment of viral infections, at least half of which are intended to treat HIV infections. A similar number of compounds are also under preclinical or clinical development, at least half of which can be expected to reach the antiviral drug market. Overall, antiviral strategies seem to target the inhibition of viral DNA polymerase for the treatment of DNA virus infections, helicase/NTPase for the treatment of HSV, $\mathrm{HCV}$ or SARS-CoV infections, IMP dehydrogenase for the treatment of HCV and some (-)RNA virus (for example, arena- and bunyavirus) infections, SAH hydrolase for the treatment of other (-)RNA virus infections such as Ebola and Marburg virus or $( \pm)$ RNA virus infections such as rotavirus, and RNA-dependent RNA polymerase for the treatment of other $(+)$ RNA virus (flavivirus and hepacivirus) infections. Finally, IFNs seem to be good therapeutic agents for those viral infections like those caused by coxsackieviruses, hepatitis $\mathrm{B}$ and $\mathrm{C}$ viruses and SARS-CoV, that, as yet, cannot be sufficiently curbed by other therapeutic or prophylactic approaches.
1. De Clercq, E. Strategies in the design of antiviral drugs. Nature Rev. Drug Discov. 1, 13-25 (2002). Highlights the different mechanistic strategies that could be followed or envisaged towards the design and development of antiviral drugs.

2. De Clercq, E. Clinical potential of the acyclic nucleoside phosphonates cidofovir, adefovir, and tenofovir in treatment of DNA virus and retrovirus infections. Clin. Microbiol. Rev. 16, 569-596 (2003).

Provides a comprehensive review of the clinical potential of three nucleotide analogues in the treatment of herpes-, pox-, adeno- and papillomavirus infections (cidofovir), HBV infection (adefovir) and HIV infections (tenofovir).

3. Andrei, G., Snoeck, R., Vandeputte, M. \& De Clercq, E. Activities of various compounds against murine and primate polyomaviruses. Antimicrob. Agents Chemother. 41, 587-593 (1997).

4. Andrei, G., Snoeck, R., Schols, D. \& De Clercq, E. Induction of apoptosis by cidofovir in human papillomavirus (HPV)-positive cells. Oncol. Res. 12, 397-408 (2001).

5. Abdulkarin, B. et al. Antiviral agent cidofovir restores p53 function and enhances the radiosensitivity in HPV associated cancers. Oncogene 21, 2334-2346 (2002)

6. Andrei, G. et al. Efficacy of PMEG [9-(2phosphonylmethoxyethyl)guanine] and its prodrug $\mathrm{CPr}$ PMEDAP [9-(2-phosphonylmethoxyethyl)-N6-cyclopropyl2,6-diamino-purine] in organotypic cultures of normal and papillomavirus (HPV)-positive keratinocytes. The 17th International Conference on Antiviral Research, 2004. Antiviral Res. 62, A61, no. 84 (2004)

7. Bordigoni, P., Carret, A.-S., Venard, V., Witz, F. \& Le Faou, A. Treatment of adenovirus infections in patients undergoing allogeneic hematopoietic stem cell transplantation. Clin. Infect. Dis. 32, 1290-1297 (2001).

8. De Clercq. E. Antiviral drugs in current clinical use. J. Clin. Virol. 30, 115-133 (2004).

9. De Clercq, E. et al. Acyclic/carbocyclic guanosine analogues as anti-herpesvirus agents. Nucleosides, Nucleotides, Nucleic Acids 20, 271-285 (2001)

10. Chen, X. et al. Structure-activity relationships of (S,Z)-2aminopurine methylenecyclopropane analogues of nucleosides. Variation of purine-6-substituents and activity against herpesviruses and hepatitis $B$ virus. J. Med. Chem. 46, 1531-1537 (2003)

11. Zhou, S. et al. Synthesis and antiviral activity of (Z)- and (E)-2,2-[bis(hydroxymethyl)cyclopropylidene]methylpurines and pyrimidines: second-generation methylenecyclopropane analogues of nucleosides. J. Med. Chem. 47, 566-575 (2004)

12. McGuigan, C. et al. Potent and selective inhibition of varicella-zoster virus (VZV) by nucleoside analogues with an unusual bicyclic base. J. Med. Chem. 42, 4479-4484 (1999).

13. McGuigan, C. et al. Highly potent and selective inhibition of varicella-zoster virus by bicyclic furopyrimidine nucleosides bearing an aryl side chain. J. Med. Chem. 43 4993-4997 (2000).

14. De Clercq, E. Highly potent and selective inhibition of varicella-zoster virus replication by bicyclic furo [2,3-d] pyrimidine nucleoside analogues. Med. Res. Rev. 23 253-274 (2003).
References 12 and 13, reviewed in reference 14 describe a new class of nucleoside analogues with unprecedented high potency as antiviral agents.

15. Crumpacker, C. S. \& Schaffer, P. A. New anti-HSV therapeutics target the helicase-primase complex. Nature Med. 8, 327-328 (2002)

16. Crute, J. J. et al. Herpes simplex virus helicase-primase inhibitors are active in animal models of human disease. Nature Med. 8, 386-391 (2002)

17. Kleymann, G. et al. New helicase-primase inhibitors as drug candidates for the treatment of herpes simplex disease. Nature Med. 8, 392-398 (2002).

References 15-17 describe a new approach and molecular target - the viral helicase-primase - for combating HSV infections.

18. Betz, U. A. K., Fischer, R., Kleymann, G., Hendrix, M. \& Rübsamen-Waigmann, $\mathrm{H}$. Potent in vivo antiviral activity of the herpes simplex virus primase-helicase inhibitor BAY 57-1293. Antimicrob. Agents Chemother. 46, 1766-1772 (2002).

19. Snoeck, R. et al. 2-Chloro-3-pyridin-3-yl-5,6,7,8 tetrahydroindolizine-1-carboxamide (CMV423), a new lead compound for the treatment of human cytomegalovirus infections. Antiviral Res. 55, 413-424 (2002).

20. Oien, N. L. et al. Broad-spectrum antiherpes activities of 4-hydroxyquinoline carboxamides, a novel class of herpesvirus polymerase inhibitors. Antimicrob. Agents Chemother. 46, 724-730 (2002).

21. Thomsen, D. R. et al. Amino acid changes within conserved region III of the herpes simplex virus and human cytomegalovirus DNA polymerase confer resistance to

4-oxo-dihydroquinolines, a novel class of herpesvirus antiviral agents. J. Virol. 77, 1868-1876 (2003).

22. Buerger, l. et al. A novel non-nucleoside inhibitor specifically targets cytomegalovirus DNA maturation via the UL89 and UL56 gene products. J. Virol. 75 9077-9086 (2001)

23. Krosky, P. M. et al. Resistance of human cytomegalovirus to benzimidazole ribonucleosides maps to two open reading frames: UL 89 and UL56. J. Virol. 72, 4721-4728 (1998).

24. Biron, K. K. et al. Potent and selective inhibition of human cytomegalovirus replication by $1263 \mathrm{~W} 94$, a benzimidazole -riboside with a unique mode of action. Antimicrob. Agents Chemother. 46, 2365-2372 (2002).

25. Krosky, P. M., Beak, M.-C. \& Coen, D. M. The human cytomegalovirus UL97 protein kinase, an antiviral drug target, is required at the stage of nuclear egress. J. Virol. 77, 905-914 (2002)

26. Koszalka, G. W. et al. Preclinical and toxicology studies of 1263W94, a potent and selective inhibitor of human cytomegalovirus replication. Antimicrob. Agents Chemother. 46, 2373-2380 (2002).

27. Lalezari, J. P. et al. Phase I dose escalation trial evaluating the pharmacokinetics, anti-human cytomegalovirus (HCMV) activity, and safety of 1263W94 in human immunodeficiency virus-infected men with asymptomatic HCMV shedding. Antimicrob. Agents Chemother. 46, 2969-2976 (2002).

28. De Clercq, E. et al. Antiviral agents active against human herpesviruses HHV-6, HHV-7 and HHV-8. Rev. Med. Virol. 11, 381-395 (2001)
29. Williams, S. L. et al. In vitro activities of benzimidazole $\mathrm{D}$ - and $\mathrm{L}$-ribonucleosides against herpesviruses. Antimicrob. Agents Chemother. 47, 2186-2192 (2003).

30. Mahy, B. W. J. An overview on the use of a viral pathogen as a bioterrorism agent: why smallpox? Antiviral Res. 57, 1-5 (2003).

31. Bauer, D. J. in International Encyclopedia of Pharmacology and Therapeutics Vol. 1, 35-113 (Pergamon Press, Oxford, United Kingdom, 1972).

32. Safrin, S., Cherrington, J. \& Jaffe, H. S. Clinical uses of cidofovir. Rev. Med. Virol. 7, 145-156 (1997).

33. Baker, R. O., Bray, M. \& Huggins, J. W. Potential antiviral therapeutics for smallpox, monkeypox and other orthopoxvirus infections. Antiviral Res. 57, 13-23 (2003)

34. Smee, D. F. \& Sidwell, R. W. A review of compounds exhibiting anti-orthopoxvirus activity in animal models. Antiviral Res. 57, 41-52 (2003).

35. De Clercq, E. Vaccinia virus inhibitors as a paradigm for the chemotherapy of poxvirus infections. Clin. Microbiol. Rev. 14, 382-397 (2001).

36. Neyts, J. \& De Clercq, E. Therapy and short-term prophylaxis of poxvirus infections: historical background and perspectives. Antiviral Res. 57, 25-33 (2003).

37. De Clercq, E. \& Neyts, J. Therapeutic potential of nucleoside/nucleotide analogues against poxvirus infections. Rev. Med. Virol. 14, 295-306 (2004).

38. De Clercq, E. Cidofovir in the treatment of poxvirus infections. Antiviral Res. 55, 1-13 (2002).

39. Kern, E. R. et al. Enhanced inhibition of orthopoxvirus replication in vitro by alkoxyalkyl esters of cidofovir and cyclic cidofovir. Antimicrob. Agents Chemother. 46, 991-995 (2002)

40. Aldern, K. A., Ciesla, S. L., Winegarden, K. L. \& Hostetler K. Y. Increased antiviral activity of 1-Ohexadecyloxypropyl-[2-14C]cidofovir in MRC-5 human lung fibroblasts is explained by unique cellular uptake and metabolism. Mol. Pharmacol. 63, 678-681 (2003).

41. Neyts, J., Leyssen, P., Verbeken, E. \& De Clercq, E. Efficacy of cidofovir in a murine model for disseminated/progressive vaccinia. Antimicrob. Agents Chemother. 48, 2267-2273 (2004)

Presents an experimental animal model for a disseminated poxvirus infection that can occur in an immunocompromised host and that responded successfully to systemic cidofovir treatment.

42. De Clercq, E. Potential of acyclic nucleoside phosphonates in the treatment of DNA virus and retrovirus infections. Expert Rev. Antiinfect. Ther. 1, 21-43 (2003).

43. Marcellin, P. et al. Adefovir dipivoxil for the treatment of hepatitis $\mathrm{B}$ e antigen-positive chronic hepatitis $\mathrm{B}$. N. Engl. J. Med. 348, 808-816 (2003).

44. Hadziyannis, S. J. et al. Adefovir dipivoxil for the treatment of hepatitis $\mathrm{B}$ e antigen-negative chronic hepatitis $\mathrm{B}$. N. Engl. J. Med. 348, 800-807 (2003)

45. Buti, M. \& Esteban, R. Entecavir, FTC, L-FMAU, LdT and others. J. Hepatol. 39, S139-S142 (2003).

46. Lai, C.-L. et al. Entecavir is superior to lamivudine in reducing hepatitis $B$ virus DNA in patients with chronic hepatitis B infection. Gastroenterology 123, 1831-1838 (2002)

47. Marion, P. L., Salazar, F. H., Winters, M. A. \& Colonno, R. J. Potent efficacy of entecavir (BMS-200475) in a duck model of hepatitis B virus replication. Antimicrob. Agents Chemother. 46, 82-88 (2002). 
48. Levine, S. et al. Efficacies of entecavir against lamivudineresistant hepatitis $\mathrm{B}$ virus replication and recombinant polymerases in vitro. Antimicrob. Agents Chemother. 46 2525-2532 (2002)

49. Peek, S. F. et al. Antiviral activity of clevudine [L-FMAU, (1-(2-fluoro-5-methyl- $\beta,\llcorner$-arabinofuranosyl)uracil)] against woodchuck hepatitis virus replication and gene expression in chronically infected woodchucks (Marmota monax). Hepatology 33, 254-266 (2001).

50. Menne, S. et al. Immunogenic effects of woodchuck hepatitis virus surface antigen vaccine in combination with antiviral therapy: breaking of humoral and cellular immune tolerance in chronic woodchuck hepatitis virus infection. Intervirology 45, 237-250 (2002).

51. Hernandez-Santiago, B. et al. Pharmacology of $\beta$-L-thymidine and $\beta-\llcorner-2$-deoxycytidine in HepG2 cells and primary human hepatocytes: relevance to chemotherapeutic efficacy against hepatitis B virus. Antimicrob. Agents Chemother. 46, 1728-1733 (2002)

52. Krishnan, P. et al. Novel role of 3-phosphoglycerate kinase, a glycolytic enzyme, in the activation of L-nucleoside analogs, a new class of anticancer and antiviral agents. J. Biol. Chem. 278, 36726-36732 (2003)

53. Shen, $Y$ et al Selective inhibition of anthrax edema factor by adefovir, a drug for chronic hepatitis $B$ virus infection. Proc. Natl Acad. Sci. USA 101, 3242-3247 (2004).

54. Ledford, R. M. et al. VP1 sequencing of all human rhinovirus serotypes: insights into genus phylogeny and susceptibility to antiviral capsid-binding compounds. J. Virol. 78, 3663-3674 (2004).

55. Romero, J. R. Pleconaril: a novel antipicornaviral drug. Expert Opin. Investig. Drugs 10, 369-379 (2001)

56. Schiff, G. M. \& Sherwood, J. R. Clinical activity of pleconaril in an experimentally induced Coxsackie A21 respiratory infection. J. Infect. Dis. 181, 20-26 (2000)

57. Rotbart, H. A. \& Webster, A. D. Treatment of potentially life-threatening enterovirus infections with pleconaril. Clin. Infect. Dis. 32, 228-235 (2001)

58. Hayden, F. G. et al. Oral pleconaril treatment of picornavirus-associated viral respiratory illness in adults: efficacy and tolerability in phase II clinical trials. Antiviral Ther. 7, 53-65 (2002).

59. Hayden, F. G. et al. Efficacy and safety of oral pleconaril for treatment of colds due to picornaviruses in adults: results of 2 double-blind, randomized, placebo-controlled trials.

Clin. Infect. Dis. 36, 1523-1532 (2003).

60. Padalko, E. et al. Mycophenolate mofetil inhibits the development of Coxsackie B3-virus-induced myocarditis in mice. BMC Microbiol. 3, 25 (2003)

61. Padalko, E. et al. The IFN inducer Ampligen [poly(l)-poly $\left.\mathrm{C}_{12} \mathrm{U}\right)$ ] markedly protects mice against Coxsackie B3 virus-induced myocarditis. Antimicrob. Agents Chemother. 48, 267-274 (2004).

62. Gritsun, T. S., Lashkevich, V. A. \& Gould, E. A. Tick-borne encephalitis. Antiviral Res. 57, 129-146 (2003).

63. Leyssen, P., Charlier, N., Paeshuyse, De Clercq, E. \& Neyts, J. Prospects for antiviral therapy. Adv. Virus Res. 61, 511-553 (2003).

64. Morrey, J. D., Smee, D. F., Sidwell, R. W. \& Tseng, C Identification of active antiviral compounds against a New York isolate of West Nile virus. Antiviral Res. 55, 107-116 (2002)

65. Leyssen, P. et al. Acute encephalitis, a poliomyelitis-like syndrome and neurological sequelae in a hamster mode for flavivirus infections. Brain Pathol. 13, 279-290 (2003)

66. Leyssen, P. et al. IFNs, IFN inducers, and IFN-ribavirin in treatment of flavivirus-induced encephalitis in mice. Antimicrob. Agents Chemother. 47, 777-782 (2003). References 65 and 66 describe a new experimental animal model for flavivirus-induced encephalitis that was favourably affected by treatment with IFN and IFN inducers.

67. Charrel, R. N. \& de Lamballerie, X. Arenaviruses other than Lassa virus. Antiviral Res. $57,89-100$ (2003).

68. Andrei, G. \& De Clercq, E. Inhibitory effect of selected antiviral compounds on arenavirus replication in vitro. Antiviral Res. 14, 287-300 (1990).

69. McCormick, J. B. et al. Lassa fever. Effective therapy with ribavirin. N. Engl. J. Med. 314, 20-26 (1986).
This classic paper documents the efficacy of ribavirin in the treatment of one of the most deadly haemorrhagic fever virus infections, Lassa fever.

70. Sidwell, R. W. \& Smee, D. F. Viruses of the Bunya- and Togaviridae families: potential as bioterrorism agents and means of control. Antiviral Res. 57, 101-111 (2003).

71. Clement, J. P. Hantavirus. Antiviral Res. 57, 121-127 (2003).

72. Case records of the Massachusetts General Hospital Weekly clinicopathological exercises. Case 21-1998. A 32-year-old woman with pharyngeal spasms and paresthesias after a dog bite. N. Engl. J. Med. $\mathbf{3 3 9}$ 105-112 (1998).

73. Bray, M. Defense against filoviruses used as biologica weapons. Antiviral Res. 57, 53-60 (2003).

74. Jahrling, P. B. et al. Evaluation of immune globulin and recombinant IFN- $\alpha 2 b$ for treatment of experimental Ebola virus infections. J. Infect. Dis. 179, S224-S234 (1999).

75. De Clercq, E. S-Adenosylhomocysteine hydrolase inhibitors as broad-spectrum antiviral agents. Biochem. Pharmacol. 36, 2567-2575 (1987).

76. De Clercq, E. et al. Broad-spectrum antiviral activities of neplanocin A, 3-deazaneplanocin A, and their $5^{\prime}$-nor derivatives. Antimicrob. Agents Chemother. 33 1291-1297 (1989).

77. Bray, M., Driscoll, J. \& Huggins, J. W. Treatment of letha Ebola virus infection in mice with a single dose of an S-adenosyl-L-homocysteine hydrolase inhibitor. Antiviral Res. 45, 135-147 (2000).

78. Bray, M., Raymond, J. L., Geisbert, T. \& Baker, R. O. 3-Deazaneplanocin A induces massively increased IFN- $\alpha$ production in Ebola virus-infected mice. Antiviral Res. 55 151-159 (2002).

79. Carter, W. A. \& De Clercq, E. Viral infection and host defense (many aspects of viral infection and recovery can be explained by the modulatory role of double-stranded RNA). Science 186, 1172-1178 (1974).

80. Tan, S.-L., Pause, A., Shi, Y. \& Sonenberg, N. Hepatitis C therapeutics: current status and emerging strategies. Nature Rev. Drug Discov. 1, 867-881 (2002) Focuses on the genomic structure of $\mathrm{HCV}$ and the different viral proteins encoded by the viral genome that could be targets for chemotherapeutic intervention.

81. Hadziyannis, S. J. et al. PeglFN- $\alpha 2 a$ and ribavirin combination therapy in chronic hepatitis C. Ann. Intern. Med. 140, 346-355 (2004)

82. Drusano, G. L. \& Preston, S. L. A 48-week duration of therapy with pegylated IFN $\alpha 2 \mathrm{~b}$ plus ribavirin may be to short to maximize long-term response among patients infected with genotype- 1 hepatitis $C$ virus. J. Infect. Dis. 189, 964-970 (2004)

83. Borowski, P. et al. Halogenated benzimidazoles and benzotriazoles as inhibitors of the NTPase/helicase activities of hepatitis $\mathrm{C}$ and related viruses. Eur. J. Biochem. 270, 1645-1653 (2003).

84. Lamarre, D. et al. An NS3 protease inhibitor with antivira effects in humans infected with hepatitis $C$ virus. Nature 426, 186-189 (2003)

First description of a protease inhibitor that seems to inhibit the replication of $\mathrm{HCV}$ in patients.

85. Baginski, S. G. et al. Mechanism of action of a pestivirus antiviral compound. Proc. Natl Acad. Sci. USA 97 7981-7986 (2000)

86. Sun, J.-H. et al. Specific inhibition of bovine viral diarrhea virus replicase. J. Virol. 77, 6753-6760 (2003).

87. Paeshuyse, J. et al. A novel highly selective inhibitor of pestivirus replication that targets the viral RNA dependent RNA polymerase. The 17th International Conference on Antiviral Research, 2004. Antiviral Res. 62, A84, no. 147 (2004).

88. Stuyver, L. J. et al. Ribonucleoside analogue that blocks replication of bovine viral diarrhea and hepatitis $\mathrm{C}$ viruses in culture. Antimicrob. Agents Chemother 47, 244-254 (2003).

89. Krug, R. M. The potential use of influenza virus as an agent for bioterrorism. Antiviral Res. 57, 147-150 (2003).

90. Koopmans, M. et al. Transmission of H7N7 avian influenza A virus to human being during a large outbreak in commercial poultry farms in the Netherlands. Lancet $\mathbf{3 6 3}$ 587-593 (2004).

91. Fouchier, R. A. M. et al. Avian influenza A virus (H7N7) associated with human conjunctivitis and a fatal case of acute respiratory distress syndrome. Proc. Natl Acad. Sci. USA 101, 1356-1361 (2004).
92. von Itzstein, M. et al. Rational design of potent sialidasebased inhibitors of influenza virus replication. Nature $\mathbf{3 6 3}$ 418-423 (1993).

93. Kim, C. U. et al. Influenza neuraminidase inhibitors possessing a novel hydrophobic interaction in the enzyme active site: design, synthesis, and structural analysis of carbocyclic sialic acid analogues with potent antiinfluenza activity. J. Am. Chem. Soc. 119, 681-690 (1997)

94. Lam, S.-K. Nipah virus - a potential agent of bioterrorism? Antiviral Res. 57, 113-119 (2003).

95. van den Hoogen, B. G. et al. A newly discovered human pneumovirus isolated from young children with respiratory tract disease. Nature Med. 7, 729-724 (2001).

96. van den Hoogen, B. G. et al. Prevalence and clinical symptoms of human metapneumovirus infection in hospitalized patients. J. Infect. Dis. 188, 1571-1577 (2003)

97. Zambon, M. C., Stockton, J. D., Clewley, J. P. \& Fleming, D. M. Contribution of influenza and respiratory syncytial virus to community cases of influenza-like illness: an observational study. Lancet 358, 1410-1416 (2001).

98. Huntley, C. C. et al. RFI-641, a potent respiratory syncytial virus inhibitor. Antimicrob. Agents Chemother. 46 841-847 (2002)

99. Peiris, J. S. et al. Coronavirus as a possible cause of severe acute respiratory syndrome. Lancet $\mathbf{3 6 1}$ 1319-1325 (2003)

100. Lee, N. et al. A major outbreak of severe acute respirator syndrome in Hong Kong. N. Engl. J. Med. 348 , 1986-1994 (2003).

101. Ksiazek, T. G. et al. A novel coronavirus associated with severe acute respiratory syndrome. N. Engl. J. Med. $\mathbf{3 4 8}$ 1953-1966 (2003)

102. Drosten, C. et al. Identification of a novel coronavirus in patients with severe acute respiratory syndrome. N. Engl. J. Med. 348, 1967-1976 (2003).

103. Kuiken, T. et al. Newly discovered coronavirus as the primary cause of severe acute respiratory syndrome. Lancet 362, 263-270 (2003).

104. Fouchier, R. A. et al. Koch's postulates fulfilled for SARS virus. Nature 423, 240 (2003).

105. Stadler, K. et al. SARS - beginning to understand a new virus. Nature Rev. Microbiol. 1, 209-218 (2003). Describes the genomic structure of the SARS coronavirus and the viral gene products that could potentially be targeted by antiviral agents.

106. Li, W. et al. Angiotensin-converting enzyme 2 is a functional receptor for the SARS coronavirus. Nature $\mathbf{4 2 6}$ 450-454 (2003)

107. Wong, S. K., Li, W., Moore, M. J., Choe, H. \& Farzan, M. A 193-amino acid fragment of the SARS coronavirus $S$ protein efficiently binds angiotensin-converting enzyme 2 . J. Biol. Chem. 279, 3197-3201 (2004).

108. Sui, J. et al. Potent neutralization of severe acute respiratory syndrome (SARS) coronavirus by a human $\mathrm{mAb}$ to $\mathrm{S} 1$ protein that blocks receptor association. Proc. Natl Acad. Sci. USA 101, 2536-2541 (2004).

109. Towler, P. et al. ACE2 X-ray structures reveal a large hinge-bending motion important for inhibitor binding and catalysis. J. Biol. Chem. 279, 17996-18007 (2004).

110. Anand, K., Ziebuhr, J., Wadhwani, P., Mesters, J. R. \& Hilgenfeld, R. Coronavirus main proteinase ( $3 \mathrm{CL}^{\text {pro }}$ ) structure: basis for design of anti-SARS drugs. Science 300, 1763-1767 (2003)

111. Chou, K.-C., Wei, D. Q. \& Zhong, W.-Z. Binding mechanism of coronavirus main proteinase with ligands and its implication to drug design against SARS Biochem. Biophys. Res. Commun. 308, 148-151 (2003).

112. Yang, H. et al. The crystal structures of severe acute respiratory syndrome virus main protease and its complex with an inhibitor. Proc. Nat/ Acad. Sci. USA 100 13190-13195 (2003).

113. Tanner, J. A. et al. The severe acute respiratory syndrome (SARS) coronavirus NTPase/helicase belongs to a distinc class of $5^{\prime}$ to $3^{\prime}$ viral helicases. J. Biol. Chem. 278, 39578-39582 (2003)

114. Xu, X. et al. Molecular model of SARS coronavirus polymerase: implications for biochemical functions and drug design. Nucleic Acids Res. 31, 7117-7130 (2003).

115. Barnard, D. L. et al. Inhibition of severe acute respiratory syndrome-associated coronavirus (SARSCoV) by calpain inhibitors and $\beta-\mathrm{D}-\mathrm{N}^{4}$-hydroxycytidine. Antiviral Chem. Chemother. 15, 15-22 (2004). 
REVIEWS

116. Balzarini, J. et al. Inhibitory activity of vancomycin, eremomycin and teicoplanin aglycon derivatives against feline and human (that is, SARS) coronaviruses. The 17th International Conference on Antiviral Research, 2004. Antiviral Res. 62, A59, no. 78 (2004).

117. Balzarini, J. et al. Mannose-specific plant lectins are potent inhibitors of coronavirus infection including the virus causing SARS. The 17th International Conference on Antiviral Research, 2004. Antiviral Res. 62, A76, no. 122 (2004)

118. Vijgen, L. et al. Antiviral effect of plant compounds of the Alliaceae family against the SARS coronavirus. The 17 th International Conference on Antiviral Research, 2004. Antiviral Res. 62, A76, no. 123 (2004).

119. Cinatl, J. et al. Glycyrrhizin, an active component of liquorice roots, and replication of SARS-associated coronavirus. Lancet 361, 2045-2046 (2003).

120. Cinatl, J. et al. Treatment of SARS with human IFNs. Lancet 362, 293-294 (2003).

121. Haagmans, B. L. et al. Pegylated IFN- $\alpha$ protects type 1 pneumocytes against SARS coronavirus infection in macaques. Nature Med. 10, 290-293 (2004). Describes how IFN can be considered as one of the best options to prevent the spread of SARS, provided that it is administered sufficiently early following the infection.
122. De Clercq, E. in Combination Therapy of AIDS (eds De Clercq, E. \& Vandamme, A.-M.) 1-24 (Birkhauser Verlag, Basel, Switzerland, 2004).

123. De Clercq, E. in Advances in Antiviral Drug Design. (ed. De Clercq, E.) Vol. 4 1-62 (Elsevier, Amsterdam, The Netherlands, 2004).

124. De Clercq, E. HIV chemotherapy and prophylaxis: new drugs, leads and approaches. Int. J. Biochem. Cell Biol. 36, 1800-1822 (2004).

125. De Clercq, E. The bicyclam AMD3100 story. Nature Rev. Drug Discov. 2, 581-587 (2003)

Describes a potent anti-HIV agent, originally discovered as an impurity, that eventually proved to be an effective mobilizer of stem cells with potential application in several non-infectious diseases.

126. Li, F. et al. PA-457: a potent HIV inhibitor that disrupts core condensation by targeting a late step in Gag processing. Proc. Natl Acad. Sci. USA 100 13555-13560 (2003)

Acknowledgements

Special thanks are due to C. Callebaut for invaluable editorial assistance.

Competing interests statement

The author declares no competing financial interests.

\section{(a) Online links}

\section{DATABASES}

The following terms in this article are linked online to:

Entrez: http://www.ncbi.nlm.nih.gov/Entrez/

Bordetella pertussis | camelpox | cowpox | Crimean-Congo haemorrhagic fever virus | Eastern equine encephalitis virus | Ebola virus | EBV | echovirus | Guanarito virus | HBV | HCMV | hepatitis A virus | HHV-6 | HHV-7 | HIV | HSV-1 | HSV-2 | human metapneumovirus | influenza A virus | influenza B virus | Junin virus | KSHV | Lassa virus | Machupo virus | Marburg virus | monkeypox | Nipah virus | poliovirus | Pseudomonas aeruginosa | Rabies virus | Rift Valley fever virus | RSV | SARS-CoV | tick-borne encephalitis virus | UL56 | UL89 | UL97 | vaccinia | variola | Venezuelan equine encephalitis virus | VZV | Western equine encephalitis virus | Yersinia pestis

Protein Data Bank: http://www.rcsb.org/pdb/ 3CLpro

\section{FURTHER INFORMATION}

CDC Category A pathogen list

http://www.bt.cdc.gov/agent/agentlist-category.asp

\section{SUPPLEMENTARY INFORMATION:}

See online article: S1 (figure)

Access to this links box is available online. 